\title{
Olfactory perireceptor and receptor events in moths: a kinetic model revised
}

\author{
Karl-Ernst Kaissling
}

Received: 11 February 2009/Revised: 9 July 2009/ Accepted: 10 July 2009/Published online: 21 August 2009

(C) The Author(s) 2009. This article is published with open access at Springerlink.com

\begin{abstract}
Modelling reveals that within about $3 \mathrm{~ms}$ after entering the sensillum lymph, $17 \%$ of total pheromone is enzymatically degraded while $83 \%$ is bound to the pheromone-binding protein (PBP) and thereby largely protected from enzymatic degradation. The latter proceeds within minutes, 20,000-fold more slowly than with the free pheromone. In vivo the complex pheromone-PBP interacts with the receptor molecule. At weak stimulation the half-life of the active complex is $0.8 \mathrm{~s}$ due to the postulated pheromone deactivation. Most likely this process is enzymatically catalysed; it changes the PBP into a scavenger form, possibly by interference with the C-terminus. The indirectly determined PBP concentration $(3.8 \mathrm{mM})$ is close to direct measurements. The calculated density of receptor molecules within the plasma membrane of the receptor neuron reaches up to 6,000 units per $\mu \mathrm{m}^{2}$. This is compared with the estimated densities of the sensory-neuron membrane protein and of ion channels. The $\mathrm{EC}_{50}$ of the model pheromone-PBP complex interacting with the receptor molecules is $6.8 \mu \mathrm{M}$, as compared with the $\mathrm{EC}_{50}=1.5 \mu \mathrm{M}$ of bombykol recently determined using heterologous expression. A possible mechanism widening the range of stimulus intensities covered by the dose-response curve of the receptorpotential is proposed.
\end{abstract}

K.-E. Kaissling $(\bowtie)$

Max-Planck-Institut fuer Verhaltensphysiologie/Ornithologie,

Seewiesen, 82319 Starnberg, Germany

e-mail: Kaissling@ orn.mpg.de
Keywords Pheromone binding protein .

Pheromone deactivation - Pheromone degradation .

Olfactory receptor-potential - Receptor molecule density
Abbreviations
PBP Pheromone-binding protein
PDE Pheromone degrading enzyme
SNMP Sensory neuron membrane protein
Model N Model with pheromone deactivation by means of the hypothetical enzyme $\mathrm{N}$
Model R Model with pheromone deactivation by the receptor molecule $\mathrm{R}$ as a catalyst
Model S Model with spontaneous pheromone deactivation

\section{Reaction partners}

A, $A_{\text {tot }}$ A-form of PBP, with C-terminus in

$\mathrm{B} \quad \mathrm{B}$-form of PBP, with C-terminus out

B* Deactivated B-form of PBP, scavenger form

$\mathrm{E}, \mathrm{E}_{\mathrm{tot}}$ Pheromone degrading enzyme (=PDE)

F Free pheromone

$\mathrm{F}_{\text {air }} \quad$ Pheromone in air

FA Active pheromone-PBP complex, able to bind $\mathrm{R}$

FB Active pheromone-PBP complex

FB* Deactivated pheromone-PBP complex

FAR Pheromone-PBP-receptor complex

FAR $^{\prime} \quad$ Activated pheromone-PBP-receptor complex

$\mathrm{M} \quad$ Pheromone metabolite

$\mathrm{N}, \mathrm{N}_{\text {tot }}$ Hypothetical pheromone deactivating enzyme

$\mathrm{R}, \mathrm{R}_{\mathrm{tot}}$ Pheromone receptor molecule

(Concentrations of reaction partners in italics)

Terms

a Cross-sectional area of the air stream equal to the outline area of the antenna, Eq. 1

$a_{\mathrm{M}} \quad$ Membrane area of the receptor neuron, Eq. 23 
b

C

$d_{\mathrm{R}}$

$\mathrm{EC}_{50}$

$k_{\text {fall }}$

$k_{i}$

$K_{i}$

$K_{\mathrm{d} i}$

$K_{\mathrm{m} i, j}$

$n_{\mathrm{A}}$

$n_{\mathrm{h}}$

$n_{\mathrm{R}}$

$Q_{1}$

$Q_{3}$

$Q_{4}$

$Q_{5}$

$Q_{6}$

$Q_{7}$

$Q_{8}$

$Q_{\text {ads }}$

$Q_{\mathrm{h}}$

$t_{1 / 2}$

$t_{1 / 2 F A R^{\prime} \text { fall }}$

$t_{1 / 2}$

$t_{1 / 2 F A}$

$T_{c N}$

$T_{c R}$

U

$U_{\text {sat }}$

$V_{\mathrm{h}}$

$v$ $\left(\mathrm{cm}^{-1}\right)$, average catching effectiveness of the hair, Eq. 1

$=10$, estimated volume ratio of neutral/low-

$\mathrm{pH}$ zone of sensillum lymph space, Eq. 4

Density of receptor molecules in the neuron membrane, Eq. 23

$=1.5 \mu \mathrm{M}$, for bombykol-receptor molecule interaction, Nakagawa et al. 2005

$=\ln 2 / t_{1 / 2 F A R^{\prime} \text { fall }}=0.87 / \mathrm{s}$, adjusted rate constant of pheromone deactivation, chemical model, see Appendix A

Rate constants, see Figs. 4, 5

Equilibrium constants, see Figs. 4, 5

Dissociation constants, see Figs. 4, 5

Michaelis constants, see Figs. 4, 5

Avogadro number (Eq. 22)

Number of hairs per antenna Eq. 1

Number of receptor molecules per receptor neuron, Eq. 22

$=0.83$, fraction of adsorbed pheromone

binding to PBP, see Appendix A

$=0.25$, fraction of adsorbed pheromone activating receptor molecules, see Appendix A $=k_{-6} /\left(k_{6}+k_{-6}\right)=0.854$, Eq. 10

$=k_{6} /\left(k_{-5}+k_{6}\right)=0.686$, Eq. $11(=p$ in Minor and Kaissling 2003)

$=1 /\left(K_{4} C+1\right)=0.236$, Eq. 7

$=k_{6} /\left(k_{-5}+k_{6}+k_{8 \mathrm{R}}\right)=0.254$, Eq. 18

$=K_{\mathrm{d} 5 \mathrm{~N}} Q_{4} K_{4} C / K_{\mathrm{m} 7,8}$, Eq. 71

Fraction of molecules passing the area $a$ that is adsorbed on the antenna, Eq. 1

Fraction of molecules adsorbed that is caught by the hairs, Eq. 1

$=4.5 \mathrm{~min}$, half-life of $83 \%$ of pheromone in vivo (Kasang and coworkers 1971-1989)

$=0.8 \mathrm{~s}$, apparent half-life of FAR',

experimental value at the adjustment uptake

half-life of free pheromone concentration $F$,

Eqs. 19, 20

$=\ln 2 / k_{-4}=29 \mathrm{~ms}$, half-life of $\mathrm{F}$ due to reaction $\mathrm{FA} \Rightarrow \mathrm{FB}$, Eq. 21

$=153 \mathrm{~ms}$, total lifetime of FAR and FAR', model N, Eq. 25

$=24 \mathrm{~ms}$, total lifetime of FAR and FAR', model R, Eq. 26

$(\mu \mathrm{M} / \mathrm{s})$, pheromone uptake related to the volume of the olfactory hair (2.6 pl), Eq. 1

$(\mu \mathrm{M} / \mathrm{s})$, uptake at which the degrading enzyme is saturated, see Appendix A

Volume of one hair, Eq. 1

Air stream velocity, Eq. 1
$V_{\max } \quad(\mu \mathrm{M} / \mathrm{s})$, maximum velocity of pheromone deactivation, see Appendix A, Eqs. 36-38

\section{Introduction}

Experimental observations together with quantitative modelling led to the suggestion that peripheral events rather than intracellular signalling govern the kinetics of the olfactory receptor-potential in the unadapted receptor neuron (Kaissling 2001). Peripheral events include the adsorptive uptake of odorant molecules from the air space by the olfactory organ, their transport towards the olfactory receptor cell and their interactions with various olfactory proteins such as extracellular odorant-binding proteins (Vogt and Riddiford 1981; Klein 1987; Steinbrecht et al. 1992, 1995), receptor molecules of the receptor neuron (Nakagawa et al. 2005), odorant degrading enzymes (Vogt et al. 1985) and a hypothetical enzyme catalyzing the postulated odorant deactivation (Kaissling 1972). The aim of this paper is to study the contribution of each of these extracellular processes to the response characteristics of the receptor neuron.

For quantitative modelling one needs to know the initial concentration of each reaction partner and the rate constant of each reaction. Until recently only a few of these model parameters had been measured, whereas others were determined indirectly or based on assumptions. Recent studies presented structural and kinetic data on the interaction of the pheromone bombykol and the pheromonebinding protein (PBP) of the silk moth Bombyx mori. From $\mathrm{X}$-ray and NMR analysis it became known that this PBP undergoes conformational changes depending on $\mathrm{pH}$ (Sandler et al. 2000; Horst et al. 2001a, b; Klusák et al. 2003; Leal 2004) and on the presence of the ligand (Lautenschlager et al. 2005). The rate constants for pheromone binding by PBP in both conformations, the A-form and the B-form (with the C-terminus inside and outside the central binding cavity, respectively), were measured (Leal et al. 2005a). The velocities of the conformational changes of the two forms upon $\mathrm{pH}$ changes were determined in stop-flow experiments (ibid.).

Furthermore, the pheromone-degrading enzyme (PDE) of the moth Antheraea polyphemus, detected by Vogt and Riddiford (1981) and isolated by Vogt et al. (1985), was cloned, and its degradation kinetics were re-investigated (Ishida and Leal 2005). Finally, the receptor molecules for bombykol and bombykal were cloned, and the $\mathrm{EC}_{50}$ for bombykol interacting with the receptor molecules expressed in a heterologous system was determined (Nakagawa et al. 2005). The bombykol receptor molecule was also 
expressed in an "empty" olfactory neuron of Drosophila melanogaster (Syed et al. 2006).

In view of these findings, the model of perireceptor and receptor events (Kaissling 2001) needs to be updated and modified. We describe the chemical network of perireceptor events leading to the activation of receptor molecules. These processes are considered as extracellular stimulus transformation, while intracellular stimulus transduction leads from the activated receptor molecules to the depolarization of the receptor neuron, i.e. the receptor-potential. We model the kinetics of the receptor-potential following the suggestion of Kaissling (2001) that it is governed by extracellular processes, because intracellular transduction appears to be relatively rapid. This is supported by the recent analysis of intracellular signalling of Gu et al. (2009).

Modelling may help to understand the multiple functions of the PBP (Kaissling 2001), to estimate the density of receptor molecules in the receptor neuron membrane, and to distinguish the measured degradation and the postulated deactivation of the pheromone. Major attention is devoted to the unknown mechanism of odorant deactivation. Two mechanisms were discussed previously, with deactivation catalysed either by the hypothetical enzyme $\mathrm{N}$ (model N, Kaissling 1998a, 2001) or by the receptor molecules (model R; Kaissling 1998a, b). Here we treat both models and compare them with a model in which deactivation is a spontaneous, non-enzymatic process (model S). The experimental data were taken from studies of two insect species mainly, the silkmoth, B. mori and the saturniid moth, A. polyphemus.

We discuss the contribution of the PBP, the pheromone degrading enzyme, the pheromone deactivation process and the receptor molecules to the kinetics and the chemical specificity of the receptor-neuron response. Finally, we add in the discussion a possible explanation for the wide range of stimulus concentrations covered by the steady doseresponse curve of the receptor-potential.

\section{Description of the models}

The analysis presented here proceeds in two steps. The first step is the design of a chemical model, including a network of extracellular chemical reactions, the "perireceptor events" and the interaction with the receptor molecules of the receptor neuron. Its aim is to understand the kinetics of the concentration of activated receptor molecules $\left(F A R^{\prime}\right)$. The second step is a simulation of the receptor potential kinetics. A quantitative physiological model is required for understanding the connection between $F A R^{\prime}$ and the receptor potential and for understanding the striking
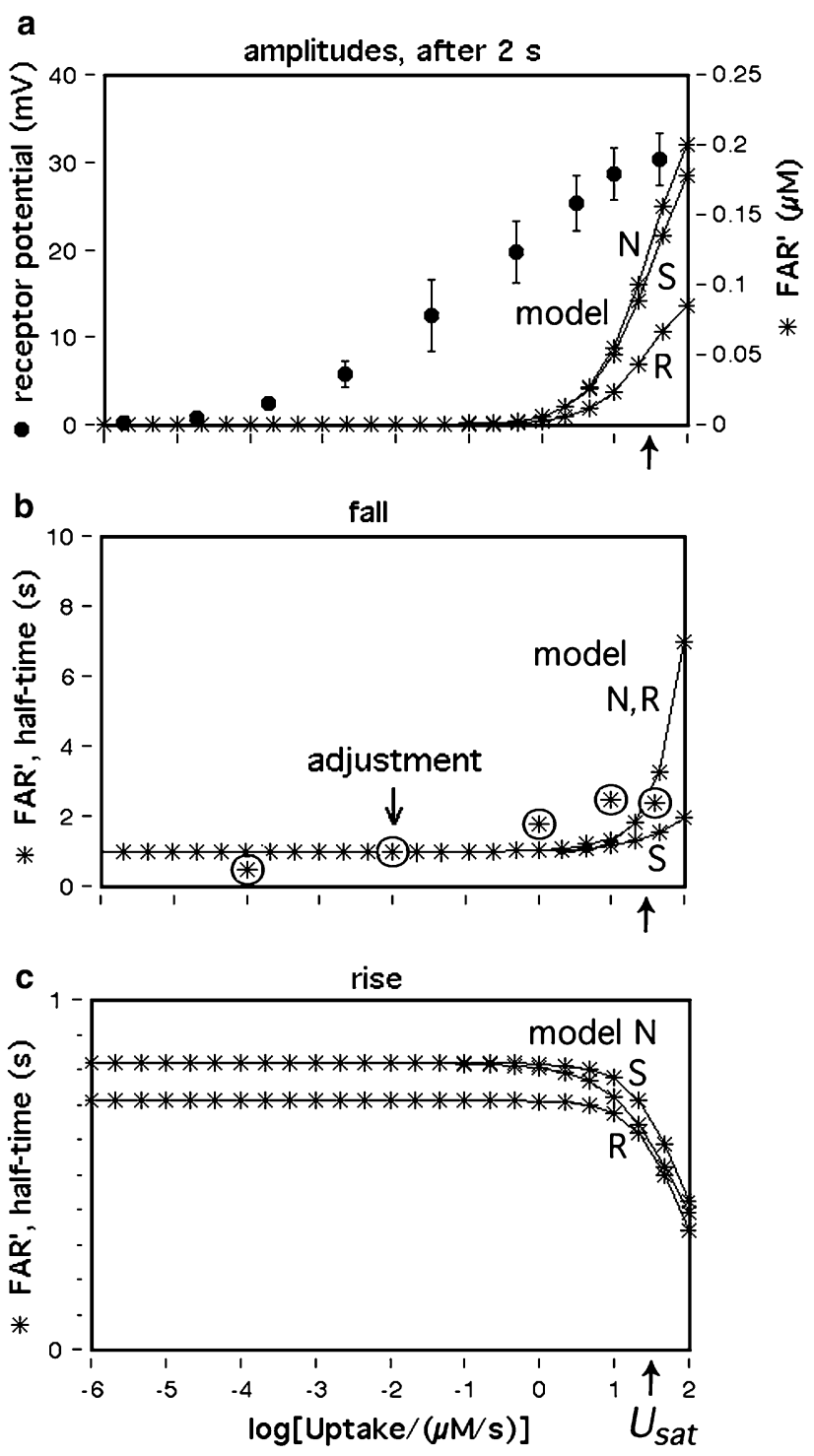

Fig. 1 Dose-response functions of the recorded receptor potential $(\mathrm{mV})$, and of $F A R^{\prime}(\mu \mathrm{M})$ produced by the chemical models $\mathrm{N}, \mathrm{R}$, and S. Abscissa: stimulus uptake $U$ (molecules adsorbed per second and per hair volume, given in $\mu \mathrm{M} / \mathrm{s})$, calibrated using the ${ }^{3} \mathrm{H}$-labelled major pheromone component (E,Z)-6,11-hexadecadienyl acetate of Antheraea polyphemus (Kaissling 1987, 1995). a Dots amplitudes of receptor-potentials extracellularly recorded from single sensilla trichodea of male moths stimulated by the pheromone for $2 \mathrm{~s}$ (Zack 1979). The three lowest values were re-measured by Blanka Pophof, Seewiesen. Asterisks concentrations of $F A R^{\prime}$, after 2-s stimulation. The theoretical maximum $\left(F A R_{\text {max }}^{\prime}\right)$ reached at $U_{\text {sat }}$ with infinitely long stimulation amounts to $F A R_{\text {max }}^{\prime}=0.24 \mu \mathrm{M}$ for models $\mathrm{N}$ and $\mathrm{S}$, and $F A R_{\text {max }}^{\prime}=0.11 \mu \mathrm{M}$ for model R. $U_{\text {sat }}$ is the uptake at which the pheromone deactivation is saturated (models $\mathrm{N}, \mathrm{R}$ ) or half-saturated (model S). b Fall of $F A R^{\prime}$ after stimulus offset. Encircled asterisks experimental half-times determined from the fall of the receptor potential (from Fig. 4d in Kaissling 1998b). At the "adjustment uptake" of $10^{-2} \mu \mathrm{M} / \mathrm{s}$ the fall of $F A R^{\prime}$ was adjusted to the experimental fall $\left(t_{1 / 2 F A R^{\prime} \text { fall }}=0.8 \mathrm{~s}\right)$. c Half-times of rise of $F A R^{\prime}$ after stimulus onset 
difference between the dose-response curves of $F A R^{\prime}$ and the receptor potential (Fig. 1a). Instead of the pending model (see a recent proposal of $\mathrm{Gu}$ et al. 2009) we use the "physiological" assumption that the relationship between $F A R^{\prime}$ and the receptor potential amplitude during their transients is the same as in the steady state (assumption G in Kaissling 2001). This allows predicting transients of the receptor potential from the transients of $F A R^{\prime}$ obtained from the chemical model. It also allows predicting changes of the steady dose-response curve of the receptor potential obtained by parameter changes of the chemical model.

The chemical model represents a flux detector as opposed to a concentration detector (Kaissling 1998a). A flux detector adsorbs the stimulus molecules depending on both the stimulus concentration within the external medium and the relative velocity of detector and medium. Flux detectors are represented by moth antennae that adsorb pheromone molecules from an airstream. Because during the $2 \mathrm{~s}$ of stimulation the stimulus molecules practically do not desorb (Kanaujia and Kaissling 1985) they accumulate and must be deactivated in order to terminate the excitation. For convenience we express the stimulus uptake $U$ and the deactivation as increase and decrease, respectively, of molecule concentrations within the olfactory sensillum per second.

Features retained from previous modelling

The following features of the previous model (Kaissling 2001) are retained in the new model:

1. After adsorption from the air space at the surface of the olfactory hair, the pheromone $(F)$ moves by random walk along the hair surface and passes through the hair wall via the pore tubules. From the pore tubules the pheromone is transported to the receptor-neuron while bound to the PBP.

2. Most of the pheromone entering the hair lumen (the fraction $Q_{1}$ ) binds to the PBP. This protein solubilizes the hydrophobic stimulus molecules and carries them to the receptor-neuron (Van den Berg and Ziegelberger 1991). A minor portion of the incoming pheromone $\left(1-Q_{1}\right)$ encounters the pheromone-degrading enzyme (E) within the sensillum lymph, is rapidly degraded to a metabolite (M) and consequently lost as a stimulus compound.

3. In vivo the pheromone-PBP complex rather than the free pheromone interacts with the receptor molecules (R) (assumption B in Kaissling 2001). A single activation of the pheromone-PBP-receptor complex is thought to elicit an elementary receptor-potential (Minor and Kaissling 2003).

4. After the pheromone-PBP and receptor molecule form a ternary complex, the receptor molecule may become activated and induce opening of ion channels. The temporal pattern of the activation of single receptor molecules is reflected by the elementary receptorpotentials observed at weak stimulus intensities (assumption C in Kaissling 2001; Minor and Kaissling 2003).

5. The pheromone-PBP complex becomes deactivated, with the pheromone remaining chemically intact (cf. assumption D in Kaissling 2001). Odorant deactivation was postulated (Kaissling 1972) in order to explain the finding that the half-life of the pheromone expected from the decline of the receptor-potential after stimulus offset (in the range of $1 \mathrm{~s}$ ) is about 300 -fold smaller than the pheromone half-life measured on the living antenna (4-5 min). Consequently, there must be a process that stops the intact pheromone present within the sensillum lymph (Kanaujia and Kaissling 1985) from stimulating the receptor neuron.

6. While bound to the PBP the pheromone is largely protected from degradation by the enzyme (E) (assumption E in Kaissling 2001). Protection of pheromone by PBP was shown in vitro by Vogt and Riddiford (1986).

7. For a flux detector of the type of model $R$, the "steady" concentration of activated receptor molecules $F A R^{\prime}$ increases in linear proportion to the uptake $U$ (Kaissling 1998a). From the various possible slopes for model $\mathrm{N}$ we choose a linear increase (assumption $\mathrm{F}$ of Kaissling 2001). In both models, the steady $F A R^{\prime}$ concentration approaches a maximum value with longtime stimulation at $U_{\text {sat }}$ when the deactivating enzyme is saturated. At $U>U_{\text {sat }}$ the fall of $F A R^{\prime}$ after the stimulus offset is delayed due to accumulation of active stimulus molecules.

8. For the simulation of the receptor potential we use (as in Kaissling 1998b, 2001) the "quasi-steady" mVamplitude measured after 2 -s stimulation in A. polyphemus, for the receptor-neuron responding to the major pheromone component $(E, Z)-6,11$-hexadecadienyl acetate (Zack 1979) (Fig. 1a). The amplitude increases over a range of uptakes from $10^{-6}$ to $10^{2} \mu \mathrm{M} / \mathrm{s}$, with a slope much shallower than the one of a linear or the hyperbolic (logistic) function.

Model improvements

The revision presented here implements the recently determined rate constants for the binding of pheromone to the PBP, for the conformational changes of the PBP and for the enzymatic pheromone degradation (see "Introduction"). Furthermore, the following improvements are included. 
1. Following a re-evaluation of the studies of Kasang (1971, 1973) and Kasang et al. $(1988,1989 a, b)$ on the pheromone degradation in vivo, the fraction of incoming pheromone lost by rapid enzymatic degradation is changed from the previously assumed $1 \%$ to the experimental average value of $17 \%$. Accordingly, the fraction of pheromone molecules adsorbed that bind to PBP is $Q_{1}=83 \%$ (see Appendix A).

2. The two forms (A and $\mathrm{B}$ ) of the $\mathrm{PBP}$ and their conformational changes (Leal et al. 2005a, b) now are included in the model. The new model considers the Bform as a carrier of the pheromone. The complex of the pheromone and the A-form, however, is chosen as the species that interacts with the receptor molecule because it binds the pheromone about 15 times less strongly than the B-form (Leal et al. 2005a).

In brief, the A-form (with the C-terminus inside the central binding cavity) occurs at low $\mathrm{pH}$ and also at neutral $\mathrm{pH}$, but at the latter only in the absence of the ligand. The $\mathrm{B}$-form (with the $\mathrm{C}$-terminus outside the cavity) occurs solely at neutral $\mathrm{pH}$ and in the presence of the ligand (Horst et al. 2001a, b; Lautenschlager et al. 2005; Damberger et al. 2007). In situ, the bulk of the sensillum lymph has a neutral pH (Kaissling and Thorson 1980; Kaissling 1995). Due to fixed negative charges, the $\mathrm{pH}$ is expected to be reduced locally within a 20 - to 50 -nm layer adjacent to the plasma membrane of the receptor neuron and around the inner ends of the pore tubules (Keil 1984a; Wojtasek and

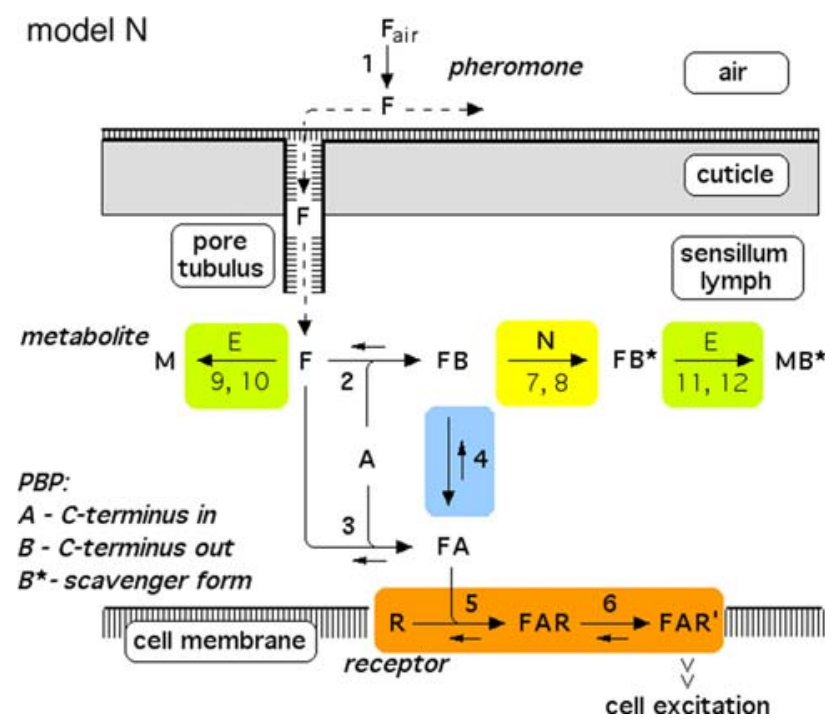

Fig. 2 Reaction network of perireceptor and receptor events within a moth olfactory sensillum. Chemical model $\mathrm{N}$, with the hypothetical enzyme $\mathrm{N}$ catalyzing the deactivation of the complex FB. Twelve reactions are numbered. Reactions 7,9 , and 11 represent binding to and dissociation from the enzymes $\mathrm{E}$ and $\mathrm{N}$. The catalytic reactions 8, 10 , and 12 are irreversible. Reaction $13\left(\mathrm{FB}^{*} \Rightarrow \mathrm{F}+\mathrm{B}^{*}\right)$ is not shown. For model parameters see Fig. 4
Leal 1999). Both forms of the PBP, however, are expected to occur everywhere in the sensillum lymph because the time needed for diffusion within the hair lumen is shorter than the lifetime of either form after the $\mathrm{pH}$ has changed.

3. In each of the three models discussed here the pheromone deactivation changes the pheromone-PBP complex to an inactive form (FB*) with $\mathrm{B}^{*}$ representing the scavenger form of the PBP. In the model $\mathrm{N}$ the hypothetical enzyme $\mathrm{N}$ deactivates the complex $\mathrm{FB}$ (Fig. 2), whereas in the model $\mathrm{R}$ the receptor molecule $\mathrm{R}$ serves as a catalyst deactivating the complex FA (Fig. 3). For comparison, we use model $\mathrm{S}$ with deactivation as a spontaneous first-order reaction that changes $\mathrm{FB}$ to $\mathrm{FB}^{*}$.

4. For simulating the receptor-potential transients, we use the chemical model with a fall time of $F A R^{\prime}$ adjusted to the experimental value of $t_{1 / 2 F A R^{\prime} \text { fall }}=0.8 \mathrm{~s}$ (Fig. 1). In addition, we discuss the dependence of $t_{1 / 2 F A R^{\prime} \text { fall }}$ on the stimulus intensity observed by Kaissling (1998b).

The chemical model

In all models (for models $\mathrm{N}$ and $\mathrm{R}$ see Figs. 2, 3, respectively) the pheromone is adsorbed by the hair (reaction 1) and diffuses along the hair surface, through the hair wall via the pore tubules, and-carried by the pheromonebinding protein - towards the receptor neuron. Entering the hair lumen the pheromone $(F)$ binds to one of two reaction partners dissolved in the sensillum lymph-either the

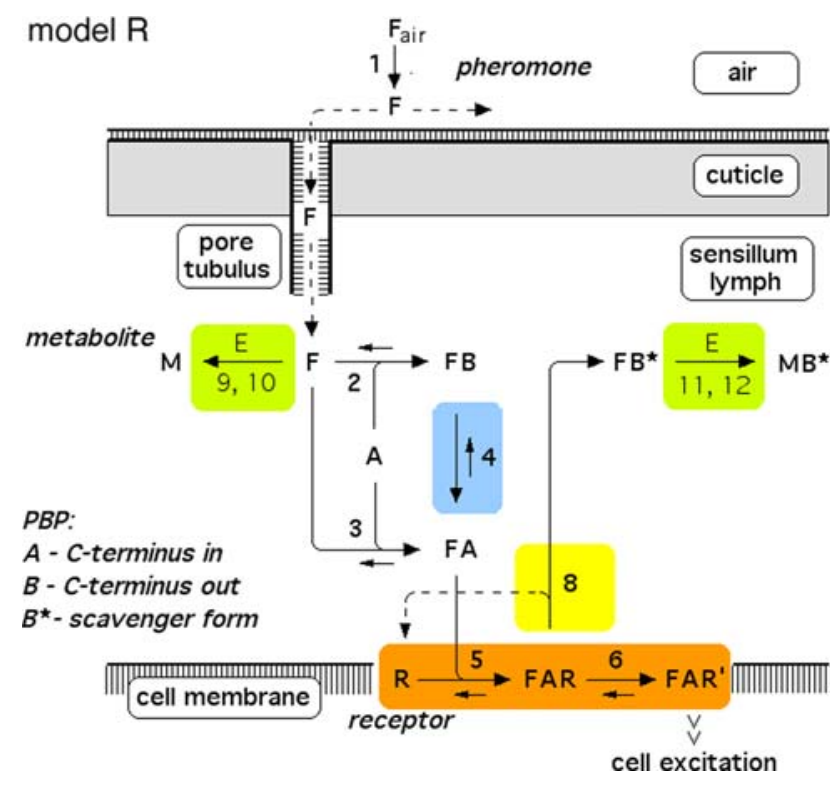

Fig. 3 Reaction network, chemical model R, with the receptor molecule catalyzing the deactivation of the complex FA. For explanations see Fig. 2. For model parameters see Fig. 5 
pheromone-degrading enzyme (E) or the A-form of the PBP (A). When $\mathrm{F}$ binds to the A-form at neutral $\mathrm{pH}$ (reaction 2), the complex $\mathrm{FB}$ is produced changing the conformation of the PBP. The binding of $\mathrm{F}$ and $\mathrm{A}$ at low $\mathrm{pH}$ forms the complex FA (reaction 3). Upon $\mathrm{pH}$-changes the complex FB may be converted into FA and back to FB (reaction 4). The complex FA is assumed to be the only species binding to the receptor molecule (R) (reaction 5). The ternary complex (FAR) may go to an activated state $\left(F^{\prime} R^{\prime}\right)$ (reaction 6), which initiates excitation of the neuron via rapid cellular signal processes.

Regarding the pheromone deactivation in model $\mathrm{N}$ we consider a version in which the hypothetical enzyme $\mathrm{N}$ binds the complex FB (reaction 7). The catalytic reaction 8 produces the deactivated complex FB*, which is unable to activate receptor molecules. In model $\mathrm{R}$ the receptor molecule $\mathrm{R}$ acts as a catalyst changing the complex FA to the deactivated form $\mathrm{FB}^{*}$ (reaction 8 ). Deactivation occurs by the spontaneous first-order reaction $\mathrm{FB} \Rightarrow \mathrm{FB}^{*}$ in model $\mathrm{S}$.

In all of the models, the free pheromone $(\mathrm{F})$ is rapidly degraded to the metabolite $(\mathrm{M})$ by the enzyme (E), via forming the complex (FE) (reaction 9) and the catalytic reaction 10. Reactions 11 and 12, respectively, represent the comparatively slow enzymatic degradation of the pheromone bound to the scavenger form $\left(\mathrm{B}^{*}\right)$. Finally, the intact pheromone $(\mathrm{F})$ may very slowly dissociate from the deactivated complex $\left(\mathrm{FB}^{*}\right)$ and serve as stimulus again. This reaction 13 is included in order to simulate the tailing of the receptor-potential observed at very strong stimuli (Kaissling 2001). Most reactions can take place in a forward and in a reversed direction, with the rate constants $k_{i}$ and $k_{-i}$, respectively. The catalytic steps 8,10 and 12 are considered to be irreversible.

\section{Model parameters}

The dynamics of the chemical model is fully determined by the rate constants of each reaction and the initial concentration of each reaction partner. In the following, the parameters of all of the reactions (1-13) will be introduced (Figs. 4, 5). They are obtained from published electrophysiological, radiometric and biochemical measurements in B. mori and A. polyphemus. Some of the model parameters are derived from special physiological quantities (Appendix A).

\section{Model N}

Reaction 1: Uptake of pheromone by the olfactory hairs. The adsorptive stimulus uptake $U$ (reaction 1) of the olfactory hair sensillum is defined as the number of pheromone molecules adsorbed per unit of time and per volume of the hair. The uptake is conveniently expressed as $\mu \mathrm{M} / \mathrm{s}$ model $\mathrm{N}$

\begin{tabular}{|c|c|c|c|}
\hline & $k_{i}$ (forward) & $k_{-i}($ reverse $)$ & \\
\hline$k_{2}$ & $0.068 /(\mathrm{s} \cdot \mu \mathrm{M})$ & $0.0071 / \mathrm{s}$ & $K_{d 2}=0.105 \mu \mathrm{M}$ \\
\hline$k_{3}$ & $0.0066 /(\mathrm{s} \cdot \mu \mathrm{M})$ & $0.011 / \mathrm{s}$ & $K_{d \beta}=1.6 \mu \mathrm{M}$ \\
\hline$k_{4}$ & $74 / s$ & $24 / s$ & $K_{4}=0.32$ \\
\hline $\begin{array}{l}k_{5 \mathrm{~N}} \\
k_{6}\end{array}$ & $\begin{array}{l}0.974 /(\mathrm{s} \cdot \mu \mathrm{M}) \\
16.8 / \mathrm{s}\end{array}$ & $\begin{array}{l}7.7 / \mathrm{s} \\
98 / \mathrm{s}\end{array}$ & $\begin{aligned} K_{\alpha 5 N} & =7.91 \mu \mathrm{M} \\
K_{6} & =5.8\end{aligned}$ \\
\hline $\begin{array}{l}k> \\
k_{B N}\end{array}$ & $\begin{array}{l}16.0 /(s \cdot \mu M) \\
49.8 / s\end{array}$ & $\begin{array}{c}300 / \mathrm{s} \\
-\cdot-\end{array}$ & $K_{m 7,8}=21.9 \mu \mathrm{M}$ \\
\hline $\begin{array}{l}k_{9} \\
k_{10}\end{array}$ & $\begin{array}{l}300 /(\mathrm{s} \cdot \mu \mathrm{M}) \\
127 / \mathrm{s}\end{array}$ & $\begin{array}{c}230 / \mathrm{s} \\
-\cdot-\end{array}$ & $K_{m 9,10}=1.2 \mu \mathrm{M}$ \\
\hline $\begin{array}{l}k_{11} \\
k_{12}\end{array}$ & $\begin{array}{l}0.015 /(\mathrm{s} \cdot \mu \mathrm{M}) \\
127 / \mathrm{s}\end{array}$ & $\begin{array}{c}230 / s \\
-\cdot-\end{array}$ & $K_{m 11,12}=24 \mathrm{mM}$ \\
\hline$k_{13}$ & $0.000008 / \mathrm{s}$ & -- & \\
\hline
\end{tabular}

Fig. 4 Parameters of model N (Fig. 2)

model $\mathrm{R}$

\begin{tabular}{|c|c|c|c|}
\hline & $k_{i}$ (forward) & $k_{-i}$ (reverse) & \\
\hline$k_{2}$ & $0.068 /(\mathrm{s} \cdot \mu \mathrm{M})$ & $0.0071 / \mathrm{s}$ & $K_{d 2}=0.105 \mu \mathrm{M}$ \\
\hline$k_{3}$ & $0.0066 /(\mathrm{s} \cdot \mu \mathrm{M})$ & $0.011 / \mathrm{s}$ & $K_{d \exists}=1.6 \mu \mathrm{M}$ \\
\hline$k_{4}$ & $74 / s$ & $24 / s$ & $K_{4}=0.32$ \\
\hline $\begin{array}{l}k_{5 R} \\
k_{6}\end{array}$ & $\begin{array}{l}6.23 /(\mathrm{s} \cdot \mu \mathrm{M}) \\
16.8 / \mathrm{s}\end{array}$ & $\begin{array}{l}7.7 / \mathrm{s} \\
98 / \mathrm{s}\end{array}$ & $\begin{aligned} K_{d 5 R} & =1.24 \mu \mathrm{M} \\
K_{6} & =5.8\end{aligned}$ \\
\hline $\begin{array}{l}k> \\
k_{B R}\end{array}$ & $41.6 / \mathrm{s}$ & $\begin{array}{l}-\cdot- \\
-\cdot-\end{array}$ & $K_{m 5,8}=7.91 \mu \mathrm{M}$ \\
\hline $\begin{array}{l}k_{9} \\
k_{10}\end{array}$ & $\begin{array}{l}300 /(s \cdot \mu \mathrm{M}) \\
127 / \mathrm{s}\end{array}$ & $\begin{array}{c}230 / s \\
-\cdot-\end{array}$ & $K_{m 9,10}=1.2 \mu \mathrm{M}$ \\
\hline $\begin{array}{l}k_{11} \\
k_{12}\end{array}$ & $\begin{array}{l}0.015 /(\mathrm{s} \cdot \mu \mathrm{M}) \\
127 / \mathrm{s}\end{array}$ & $\begin{array}{c}230 / s \\
-\end{array}$ & $K_{m 11,12}=24 \mathrm{mM}$ \\
\hline$k_{13}$ & $0.000008 / \mathrm{s}$ & --- & \\
\hline
\end{tabular}

Fig. 5 Parameters of model R (Fig. 3). The parameters different from Fig. 4 are $k_{5 R}, K_{\mathrm{d} 5 R}, k_{8 R}, K_{\mathrm{m} 5,8}$, and $\mathrm{R}_{\mathrm{tot} R}$. The parameters $\mathrm{N}_{\text {tot }}$, $k_{7}$, and $k_{-7}$ are absent

(Kaissling 2001). It is the product of the stimulus concentration in air $F_{\text {air }}$, the relative airstream velocity $v$ and a factor $b\left(\mathrm{~cm}^{-1}\right)$ representing the average "catching effectiveness" of the hair.

$U=F_{\text {air }} v b=F_{\text {air }} v \frac{a Q_{\text {ads }} Q_{\mathrm{h}}}{n_{\mathrm{h}} V_{\mathrm{h}}}$

The product $F_{\text {air }} \cdot v$ is the stimulus intensity expressed as molecules per cross-sectional area of the airstream and per 
second. The factor $b$ depends on the outline area $a$ of the antenna, the fraction $Q_{\text {ads }}$ of molecules passing a crosssectional area $a$ of the airstream that is caught by the antenna, the fraction $Q_{\mathrm{h}}$ of the molecules adsorbed on the antenna that is caught by the hairs, the volume $V_{\mathrm{h}}$ of the hairs and their number per antenna $n_{\mathrm{h}}$. For sensilla trichodea of the male antenna of A. polyphemus, we use $a=0.8 \mathrm{~cm}^{2}, Q_{\mathrm{ads}}=0.3, Q_{\mathrm{h}}=0.8, n_{\mathrm{h}}=60,000, V_{\mathrm{h}}=$ $2.6 \mathrm{pl}$ and find $b=1,231 / \mathrm{cm}$. For the shorter hairs of B. mori, we use $a=0.06 \mathrm{~cm}^{2}, Q_{\mathrm{ads}}=0.27, Q_{\mathrm{h}}=0.8$, $n_{\mathrm{h}}=17,000, V_{\mathrm{h}}=0.26 \mathrm{pl}$ and find $b=2,932 / \mathrm{cm}$. The values of $F_{\text {air }}, Q_{\text {ads }}$, and $Q_{\mathrm{h}}$ were determined using ${ }^{3}$ H-labeled pheromone applied in a turbulent air stream (Steinbrecht 1970, 1973; Kaissling 1971; Steinbrecht and Kasang 1972; Steinbrecht et al. 1989; Kanaujia and Kaissling 1985; Kaissling unpubl.).

During time intervals of a few second no desorption from the antennae was found (Kanaujia and Kaissling 1985). Because the diffusion from the hairs to other parts of the antennae is slow, the amount of pheromone adsorbed on the hairs increases during stimulus exposure. Most of the adsorbed pheromone was found to rapidly enter the hair lumen. After adsorption, the pheromone $(\mathrm{F})$ moves along the hair surface (2D diffusion), through the hair wall via the pore tubules (1D diffusion) and through the sensillum lymph towards the receptor cell (3D diffusion) (Steinbrecht 1973). For modelling diffusion (see Kaissling 1987) we use a diffusion coefficient of $90 \mu \mathrm{m}^{2} / \mathrm{s}$ for transport along the cuticle and pores and of $30 \mu \mathrm{m}^{2} / \mathrm{s}$ within the sensillum lymph while bound to the PBP. These coefficients are based on longitudinal migration of ${ }^{3} \mathrm{H}$-labeled pheromone on dried and fresh hairs, respectively (Kanaujia and Kaissling 1985). With these coefficients the pheromone molecules reach the receptor-neuron inside the hair (diameter 2-3 $\mu \mathrm{m}$ ) within an average time interval of about $10 \mathrm{~ms}$ (Kaissling 2001). Because this time is short compared with the half time of the rise of the receptor-potential, it seems adequate to assume immediate encounter of all molecular species of the reaction network. For convenience we express the amount of the membrane-bound molecular species, such as R, FAR and FAR', as concentrations within the total hair volume (about half of which is spanned by the hair lumen).

Reactions 2, 3: Binding of pheromone to PBP. The model concentration of PBP, A-form, is set to $A_{\mathrm{tot}}=3.8 \mathrm{mM}$, a value here determined indirectly (see Appendix A). The initial concentration of the B-form (existing only in the complex FB) is zero.

The association and dissociation rate constants of bombykol and the PBP of $B$. mori were determined by Leal et al. (2005a) at neutral $\mathrm{pH}: k_{2}=0.068 /(\mathrm{s} \mu \mathrm{M})$ and $k_{-2}=0.0071 / \mathrm{s}$, with the dissociation constant

$K_{\mathrm{d} 2}=\frac{k_{-2}}{k_{2}}=\frac{F \cdot A}{F B}=0.105 \mu \mathrm{M}$

and at low $\mathrm{pH}: k_{3}=0.0066 /(\mathrm{s} \mu \mathrm{M})$ and $k_{-3}=0.011 / \mathrm{s}$, with

$K_{\mathrm{d} 3}=\frac{k_{-3}}{k_{3}}=\frac{F \cdot A}{F A}=1.6 \mu \mathrm{M}$

In order to obtain the in vivo equilibrium concentrations of F, A, FA and FB, we have to consider the chance of each species to enter (by diffusion) a zone of a different $\mathrm{pH}$ : neutral $\mathrm{pH}$ in the bulk of the sensillum lymph, low $\mathrm{pH}$ within the zone of fixed negative charges adjacent to the cell membranes and the pore tubules (see above). According to the distribution of fixed anions (Keil 1984a) the volume is at least tenfold smaller for the zone of low $\mathrm{pH}$. Thus we set the ratio of the high/low $\mathrm{pH}$ zones $C=10$. Correspondingly, the formation rate of the low-pH species FA, with $k_{3}$ (and also $k_{4}$, see below) as compared with the formation rate of FB will be slowed down by the factor $C$. Therefore, we obtain for the in vivo conditions

$\frac{F \cdot A}{F A}=\frac{k_{-3} C}{k_{3}}=K_{\mathrm{d} 3} C=16 \mu \mathrm{M}$

Reaction 4: Conformational changes of PBP. The $\mathrm{pH}-$ dependent changes between B- and A-form of the PBP have been measured with the bombykol-PBP complex (Leal et al. 2005a). The respective rate constants were $k_{F B} \Rightarrow F A=k_{4}=74 / \mathrm{s}$ and $k_{F A \Rightarrow F B}=k_{-4}=24 / \mathrm{s}$. We define

$K_{4}=\frac{k_{-4}}{k_{4}}=0.324$

In order to obtain the equilibrium concentrations of FA and $\mathrm{FB}$ in vivo we have to consider that the formation of FA will be reduced by the factor $C$ (see above, reactions 2, 3 ). Instead of Eq. 5 we find for the in vivo conditions, with $C=10$,

$\frac{F B}{F A}=\frac{k_{-4} C}{k_{4}}=K_{4} C=3.24$

and,

$\frac{F A}{F A+F B}=\frac{1}{K_{4} C+1}=Q_{6}=0.236$

Reactions 5, 6: Pheromone and receptor molecule: binding and activation. The pheromone-PBP complex (FA) binds to the receptor molecule and activates it. The rate constants are for binding $k_{5 N}=0.974 /(\mathrm{s} \mu \mathrm{M})$ and $k_{-5}=7.7 / \mathrm{s}$, for activation $k_{6}=16.8 / \mathrm{s}$ and $k_{-6}=98 / \mathrm{s}$. The rate constants $k_{-5}, k_{6}$ and $k_{-6}$ resulted from the analysis of elementary 
receptor-potentials recorded from receptor-neurons of B. mori males stimulated with bombykal (Minor and Kaissling 2003).

For the calculation of $k_{5 N}=0.974 /(\mathrm{s} \mu \mathrm{M})$ and $R_{\mathrm{tot} N}=1.66 \mu \mathrm{M}$ for A. polyphemus see Appendix A. The concentration $R_{\text {tot } N}$ is given for a fictive distribution of the receptor molecules within $2.6 \mathrm{pl}$ of hair volume. The dissociation constant of the ternary complex FAR is

$K_{\mathrm{d} 5 N}=F A \cdot R / F A R=k_{-5} / k_{5 N}=7.91 \mu \mathrm{M}$.

We define

$K_{6}=F A R / F A R^{\prime}=F A R_{\max } / F A R_{\max }^{\prime}=k_{-6} / k_{6}=5.83$,

$\begin{aligned} Q_{4} & =F A R /\left(F A R+F A R^{\prime}\right)=k_{-6} /\left(k_{6}+k_{-6}\right) \\ & =F A R_{\max } / R_{\mathrm{tot}}=0.854\end{aligned}$

$Q_{5}=k_{6} /\left(k_{-5}+k_{6}\right)=0.686$

which is equivalent to $p$ in Minor and Kaissling (2003) and

$R_{\mathrm{tot}}=R+F A R+F A R^{\prime}=F A R_{\max }+F A R_{\max }^{\prime}$

Reactions 7, 8: Deactivation of the pheromone-PBP complex. In model $\mathrm{N}$ the pheromone-PBP complex FB is changed into the deactivated form $\mathrm{FB}^{*}$ by the hypothetical enzyme N, via forming the complex FBN (reaction 7) and the catalytic reaction $\mathrm{FBN} \Rightarrow \mathrm{FB}^{*}+\mathrm{N}$ (reaction 8). The enzymatic process is characterized by the Michaelis constant

$K_{\mathrm{m} 7,8}=\left(k_{-7}+k_{8 N}\right) / k_{7}=F B \cdot N / F B N$

After chosing the free parameters $N_{\text {tot }}=E_{\text {tot }}=0.5 \mu \mathrm{M}$ and $k_{-7}=300 / \mathrm{s}$, we determine $k_{8 N}=49.8 / \mathrm{s}, K_{\mathrm{m} 7,8}=$ $21.9 \mu \mathrm{M}$, and $k_{7}=15.99 /(\mathrm{s} \mu \mathrm{M})$ (see Appendix A).

Reactions 9, 10: Rapid degradation of free pheromone. For the model we use in vitro data obtained for (E,Z)-6,11-hexadecadienyl acetate and the recombinant pheromone-degrading enzyme (PDE) of A. polyphemus (Ishida and Leal 2005):

The extrapolated enzyme concentration in vivo $E_{\text {tot }}=0.5 \mu \mathrm{M}$, the catalytic rate constant $k_{10}=127 / \mathrm{s}$, and the Michaelis constant

$K_{\mathrm{m} 9,10}=\left(k_{-9}+k_{10}\right) / k_{9}=1.2 \mu \mathrm{M}$.

The respective data for the isolated PDE derived from Vogt et al. (1985) were similar:

$$
\begin{aligned}
E_{\mathrm{tot}}(\operatorname{Vogt}) & =1 \mu \mathrm{M}, \quad k_{10}(\operatorname{Vogt})=98 / \mathrm{s}, \text { and } \\
K_{\mathrm{m} 9,10}(\operatorname{Vogt}) & =2.2 \mu \mathrm{M} .
\end{aligned}
$$

The rate constants $k_{9}=300 /(\mathrm{s} \mu \mathrm{M})$ for association and $k_{-9}=230 / \mathrm{s}$ for dissociation of pheromone and enzyme are chosen in order to match the measured
$K_{\mathrm{m} 9,10}$ and to provide a rapid equilibration of substrateenzyme binding.

Reactions 11, 12: Slow degradation of pheromone bound to $P B P$. In order to simulate the slow degradation observed by Kasang and co-workers (1971-1989) on living antennae $\left(t_{1 / 2}=4.5 \mathrm{~min}\right.$, see Fig. 15$)$, we let the complex $\mathrm{FB}^{*}$ interact with the $\operatorname{PDE}(\mathrm{E})$, but at an association rate reduced by a factor of 20,000 (see Appendix A) as compared with the association rate $k_{9}$ of the free pheromone and $\mathrm{E}$. Thus, we have $k_{11}=k_{9} / 20,000=0.015 /(\mathrm{s} \mu \mathrm{M})$. We kept $k_{-11}=k_{-9}=230 / \mathrm{s}$ and $k_{12}=k_{10}=127 / \mathrm{s}$. These values result in a Michaelis constant for degradation of the complex $\mathrm{FB}^{*}$ :

$K_{\mathrm{m} 11,12}=\left(k_{-11}+k_{12}\right) / k_{11}=23.8 \mathrm{mM}$

Reaction 13: Reactivation of the intact pheromone. The reaction $F B^{*} \Rightarrow F+B^{*}$ is included for simulating the tailing of the receptor-potential observed at high stimulus intensities. The experimental data may be fitted with $k_{13}=0.000008 / \mathrm{s}$.

\section{Model R}

Because the receptor molecule $\mathrm{R}$ acts as a deactivating enzyme, the parameters $N_{\text {tot }}, k_{7}$ and $k_{-7}$ do not exist in model R. Most of the parameters of model R (Fig. 5) are the same as for model N. Exception are $k_{5 R}=6.23 /(\mathrm{s} \mu \mathrm{M})$, $k_{8 R}=41.6 / \mathrm{s}$ and $R_{\mathrm{tot} R}=0.70 \mu \mathrm{M}$ (see Appendix A). The dissociation constant of the ternary complex FAR is

$K_{\mathrm{d} 5 R}=k_{-5} / k_{5 R}=1.24 \mu \mathrm{M}$

The Michaelis constant for the deactivation of the pheromone-PBP complex FA with the receptor molecule as an enzyme is, with $k_{-5}=7.7 / \mathrm{s}$

$K_{\mathrm{m} 5,8}=F A \cdot R / F A R=\left(k_{-5}+k_{8 R}\right) / k_{5 R}=7.91 \mu \mathrm{M}$

We define

$Q_{7}=k_{6} /\left(k_{-5}+k_{6}+k_{8 R}\right)=0.254$

\section{Results}

At first the results of the chemical model will be described. Second the simulation of the receptor potential will be introduced. Finally the influence of various parameters on the simulated receptor potential will be shown. In the analysis we had to mix model parameters obtained from the two species of moths, B. mori and A. polyphemus. Although the pheromone perception in the two species shows many similarities the values calculated here from mixed data sets are very preliminary. 
The chemical model

\section{Functions of the pheromone-binding protein}

Solubilization of the pheromone The model shows the concentrations of free and bound pheromone within the sensillum lymph (Fig. 6a, b). The "steady" concentrations allow estimation of the solubilization of the pheromone. Thus, the model ratio of bound/free pheromone within the sensillum lymph $(F A+F B) / F$ is 240 or more (Table 1$)$. It
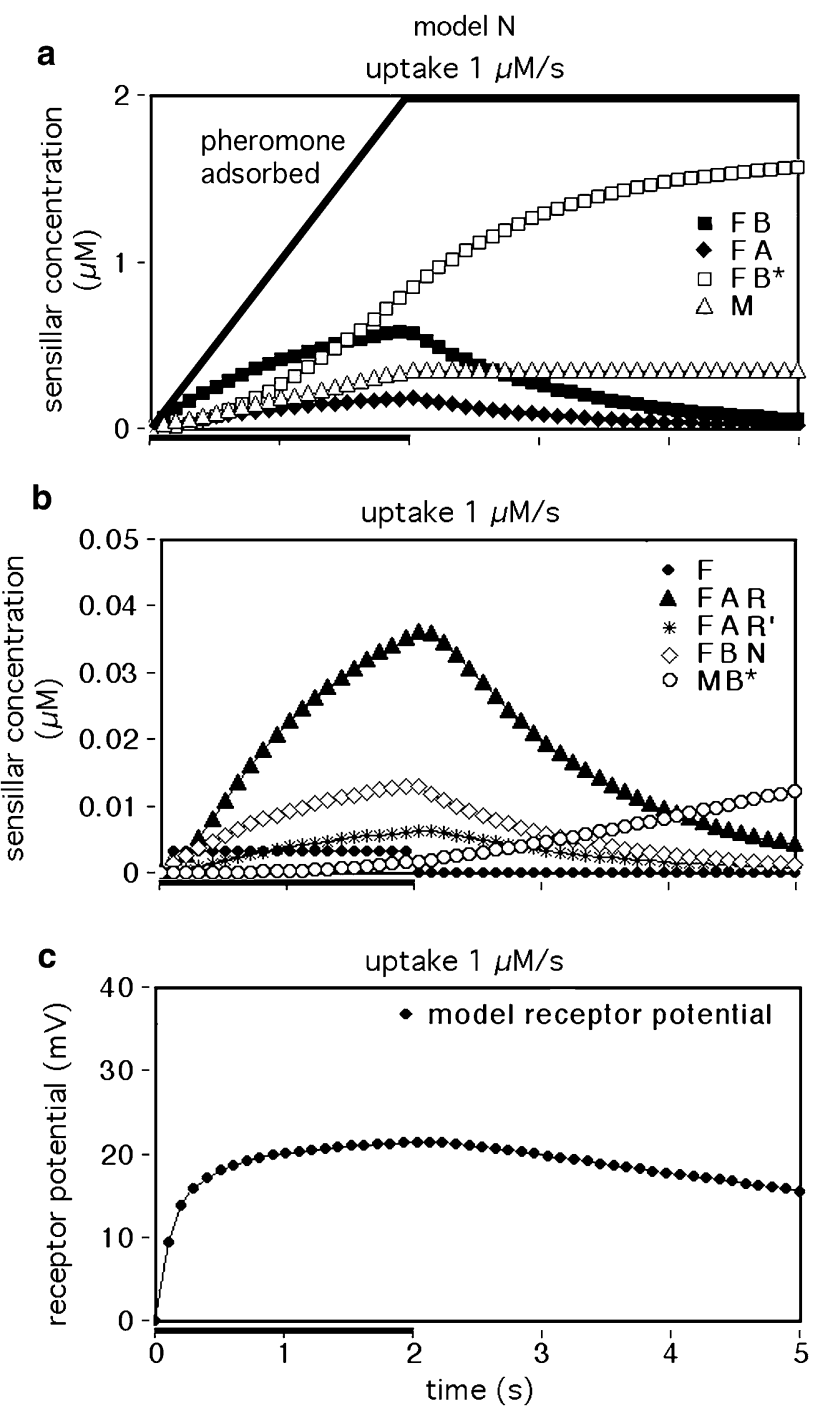

Fig. 6 Time course of model $\mathrm{N}$ variables for a 2-s stimulus. Line without symbols in a shows the total amount of pheromone adsorbed. The concentration of the free pheromone $\mathrm{F}(\mathbf{b})$ shows a rapid increase and fall, whereas $F A, F B, F B N, F A R$, and $F A R^{\prime}$ show much slower transients, with similar half-lives. After $5 \mathrm{~s}$ most of the pheromone adsorbed $(79 \%)$ is bound to the scavenger form, i.e. deactivated (FB*). The simulated receptor-potential (c) obtained after $F A R^{\prime}-\mathrm{mV}$ conversion shows the typical asymmetrical shape of the measured receptor potential, with rapid rise and slow fall
Table 1 Model concentrations $(\mu \mathrm{M})$ of free and bound pheromone at the end of 2- and 10-s stimuli with an uptake of $1 \mu \mathrm{M} / \mathrm{s}$

\begin{tabular}{llllll}
\hline & $F$ & $F A$ & $F B$ & $F A R$ & $F A R^{\prime}$ \\
\hline Model N & & & & & \\
$2 \mathrm{~s}$ & 0.0032 & 0.18 & 0.59 & 0.036 & 0.0061 \\
$10 \mathrm{~s}$ & 0.0032 & 0.23 & 0.76 & 0.047 & 0.0081 \\
Model R & & & & & \\
$2 \mathrm{~s}$ & 0.0032 & 0.18 & 0.67 & 0.016 & 0.0027 \\
$10 \mathrm{~s}$ & 0.0032 & 0.23 & 0.87 & 0.020 & 0.0034 \\
\hline
\end{tabular}

would be even larger if we include the pheromone $\mathrm{F}$ bound to the scavenger form $\left(\mathrm{FB}^{*}\right)$ that increases during and after stimulation (Fig. 6a).

That the PBP solubilizes the pheromone was shown by binding assays (Kaissling et al. 1985; Du and Prestwich 1995) and by partially replacing the sensillum lymph during electrophysiological recordings (Van den Berg and Ziegelberger 1991). In the latter experiments (with $A$. polyphemus), the pheromone, dissolved in physiological salt solution with and without PBP, was applied from a glass capillary directly to the receptor-neuron inside the hair lumen. Upon adding PBP the effectiveness of the pheromone increased by 100 -fold. Apparently, the pheromone previously adsorbed to the glass capillary was now bound to the PBP and thereby solubilized. The lower increase of solubility in this experiment as compared with the above model prediction ( $>240$-fold) could be due to a residual pheromone binding to the glass capillary.

Protection of the pheromone from enzymatic degradation In vitro experiments with the isolated pheromonedegrading enzyme (PDE) of A. polyphemus showed that the addition of PBP effectively reduced the velocity of pheromone degradation protecting the pheromone from the enzyme (Vogt and Riddiford 1986). In vivo the pheromone degradation has a biphasic time course (Kasang and coworkers 1971-1989, see Fig. 15): 17\% of the pheromone taken up by the antenna is rapidly degraded, $83 \%\left(=Q_{1}\right.$, see Appendix A) much more slowly. According to the model (inset of Fig. 15), this striking reduction of degradation velocity results mainly from the rapid formation of the complex FB protecting the pheromone from enzymatic degradation.

From in vitro studies the in vivo half-life of pheromone due to degradation - in the absence of PBP-was calculated as $15 \mathrm{~ms}$ (Vogt et al. 1985) or $13 \mathrm{~ms}$ (Ishida and Leal 2005). With the two parallel processes, degradation and binding to the PBP, the half-life $t_{1 / 2 F}$ of the free pheromone $\mathrm{F}$ entering the hair is even smaller. It may be derived after integration of Eqs. 40 and 39, respectively 
$t_{1 / 2 F}=\frac{\ln 2 Q_{1}}{A_{\text {tot }}\left(k_{2}+\frac{k_{3}}{C}\right)}$

and

$t_{1 / 2 F}=\frac{\ln 2 K_{\mathrm{m} 9,10}\left(1-Q_{1}\right)}{k_{10} E_{\mathrm{tot}}}$

With $Q_{1}$ from Kasang and coworkers (1971-1989) and the parameters of degradation in vitro from Ishida and Leal (2005), we find $t_{1 / 2 F}=2.2 \mathrm{~ms}$ for $A$. polyphemus and $t_{1 / 2 F}=2.6 \mathrm{~ms}$ from Vogt et al. (1985).

The slow phase of pheromone degradation observed in vivo (Fig. 15) is modelled by reducing the association rate constant $k_{11}$ of the deactivated pheromone-PBP complex FB* and the degrading enzyme E by 20,000-fold, as compared with $k_{9}$, the association rate constant for the free pheromone and $\mathrm{E}$.

For simplicity, in our models the pheromone bound to PBP upstream of the receptor activation, i.e. to the forms A and $\mathrm{B}$, is fully protected from degradation. In a model without protection of FA and FB $97 \%$ of the pheromone adsorbed would be degraded before reaching the receptor neuron. If FA only is unprotected, 93\% would be lostseverely impairing the sensitivity of the system.

Interaction of pheromone and receptor molecule From modelling it seems clear that in vivo the pheromone interacts with the receptor molecule while bound to the PBP (reaction 5). First, the concentration of the stimulatory complex FA is considerably higher ( $>50$-fold, see Table 1) than the concentration of free pheromone F. Second, the half-life of the complex FA (about $0.8 \mathrm{~s}$ due to deactivation, Fig. 6a) is much longer than the one of $\mathrm{F}(<3 \mathrm{~ms}$, see previous section). The half-life of an individual FA complex is

$t_{1 / 2 F A}=\ln 2 / k_{-4}=29 \mathrm{~ms}$.

In conclusion, the sensitivity of the system would be smaller by several orders of magnitude if the free pheromone $\mathrm{F}$ alone binds and activates the receptor molecule.

Pheromone deactivation In all three models the pheromone bound to PBP is deactivated by a modification of the PBP from $\mathrm{B}$ to the scavenger form $\mathrm{B}^{*}$, which changes $\mathrm{FB}$ into $\mathrm{FB}^{*}$ (reaction 8 ). This reaction keeps the pheromone chemically intact but reduces the formation of the active pheromone-PBP complex FA and thus terminates the excitation of the neuron. In two of the models the modification of the PBP is enzymatically controlled (models $\mathrm{N}$ and $\mathrm{R}$ ). In model $\mathrm{S}$ (Appendix $\mathrm{B}$ ) the modification of PBP is a spontaneous and irreversible firstorder process.
Table 2 Pheromone receptor molecules and rhodopsin

\begin{tabular}{lllll}
\hline & $\begin{array}{l}R_{\mathrm{tot}} \\
(\mu \mathrm{M})\end{array}$ & $\begin{array}{l}n_{\mathrm{R}} \text { (molec./ } \\
\text { neuron })\end{array}$ & $\begin{array}{l}d_{\mathrm{R}} \text { (molec./ } \\
\left.\mu \mathrm{m}^{2}\right)\end{array}$ & $\begin{array}{l}d_{\mathrm{R}} \\
(\% \text { rhodopsin })\end{array}$ \\
\hline \multicolumn{5}{c}{$\begin{array}{l}\text { Antheraea polyphemus, receptor neuron tuned to } \\
(\text { E,Z)-6,11-hexadecadienyl acetate }\end{array}$} \\
Model N & 1.66 & $2,598,660$ & 6,109 & 15.3 \\
Model R & 0.70 & $1,095,822$ & 2,573 & 6.4 \\
Bombyx mori, receptor neuron tuned to bombykal & \\
Model N & 1.66 & 259,866 & 4,331 & 10.8 \\
Model R & 0.70 & 109,582 & 1,826 & 4.6 \\
\hline
\end{tabular}

$R_{\text {tot }}$ fictive concentration, $n_{\mathrm{R}}$ number per neuron, $d_{\mathrm{R}}$ density per membrane area, and as \% of $d_{\mathrm{R}}$ rhodopsin with 40,000 units $/ \mu \mathrm{m}^{2}$ (Dratz and Hargrave 1983)

The number and membrane density of receptor molecules

The number of receptor molecules per receptor neuron $\left(n_{\mathrm{R}}\right)$ may be calculated from the fictive concentration $R_{\text {tot }}$ (Eqs. 52 and 54, for models $\mathrm{N}$ and $\mathrm{R}$, respectively), the hair volume $\left(V_{\mathrm{h}}\right)$ and the Avogadro number $\left(n_{\mathrm{A}}\right)$ (Table 2$)$

$n_{\mathrm{R}}=R_{\mathrm{tot}} V_{\mathrm{h}} n_{\mathrm{A}}$

The density of receptor molecules within the plasma membrane of the receptor-neuron $\left(d_{\mathrm{R}}\right)$ is obtained by dividing $n_{\mathrm{R}}$ by the dendritic membrane area $\left(a_{\mathrm{M}}\right)$

$d_{\mathrm{R}}=n_{\mathrm{R}} / a_{\mathrm{M}}$

For the receptor-neuron tuned to the pheromone $(E, Z)$ 6,11-hexadecadienyl acetate of $A$. polyphemus, we use $V_{\mathrm{h}}=2.6 \mathrm{pl}$ and $a_{\mathrm{M}}=426 \mu \mathrm{m}^{2}$ (Keil 1984b). A respective estimate for the receptor-neuron tuned to bombykal of $B$. mori uses $V_{\mathrm{h}}=0.26 \mathrm{pl}$ (from data of Steinbrecht 1973) and $a_{\mathrm{M}}=60 \mu^{2}$ (dendrite II, Steinbrecht 1973) and considers the same $U_{\text {sat }}$ as for A. polyphemus. The densities of receptor molecules are compared with the density of rhodopsin in the outer disc membrane of $d_{R}=40,000 / \mu \mathrm{m}^{2}$, which is set to $100 \%$ (Dratz and Hargrave 1983).

Generally, all numbers listed in Table 2 are 2.4-fold higher for model $\mathrm{N}$ compared with model $\mathrm{R}$. The numbers of receptor molecules per neuron are tenfold higher in $A$. polyphemus than in $B$. mori, whereas the membrane densities of both species are relatively similar. They reach up to $15 \%$ of the density of rhodopsin in the outer disc membrane of vertebrates.

\section{The temporal characteristics of the activated complex FAR'}

In our analysis, we consider average fictive concentrations of $F A R^{\prime}$. For the chemical model we determine the steadystate amplitude of $F A R^{\prime}$ and its transients, i.e. its rise and fall upon stepwise stimulation. Because the receptorpotentials reached about a constant level with 2-s stimuli, 
we consider the model $F A R^{\prime}$ concentration obtained after 2 -s stimulation as quasi-steady-state amplitude. The transients of $F A R^{\prime}$ are approximately exponential curves (Fig. 6b) and here characterized by their half-times.

For uptakes up to $1 \mu \mathrm{M} / \mathrm{s}$ the half-times of rise and fall of $F A R^{\prime}$ (Fig. 1b, c) are constant and about equal to each other. (Because the steady-state amplitudes are not fully reached after 2-s stimulation, the half-times for the rise are about $20 \%$ smaller than those for the fall). At high uptakes near $U_{\text {sat }}$ or $U_{1 / 2 \max }$, the half-times of the rise of $\mathrm{FAR}^{\prime}$ decrease (Fig. 1c), whereas those of its fall increase (Fig. 1b).

Models $\mathrm{N}$ and $\mathrm{R}$ differ with respect to the rise of $F A R^{\prime}$ depending on the initial formation of the complex FAR

$\frac{\mathrm{d} F A R}{\mathrm{~d} t}=k_{5} R_{\mathrm{tot}} F A$

With $\quad k_{5 R} R_{\mathrm{tot} R}=4.36 / \mathrm{s} \quad$ and $\quad k_{5 N} R_{\mathrm{tot} N}=1.62 / \mathrm{s}$ the formation of FAR is faster in model $\mathrm{R}$ than in models $\mathrm{N}$ and $\mathrm{S}$. This implies a faster rise of $F A R^{\prime}$ in model $\mathrm{R}$, with half-times shorter by about $100 \mathrm{~ms}$ than in model $\mathrm{N}$ (Fig. 1c). The fall of the receptor-potential after stimulus offset is faster in model $\mathrm{R}$ than in model $\mathrm{N}$, by the same absolute amount of time as its rise (about $100 \mathrm{~ms}$ ). This difference, however, is hardly noticeable because the fall of the receptor-potential takes two or more seconds.

The rise of $F A R^{\prime}$ appears to start with a delay, which is about $20 \mathrm{~ms}$ in model $\mathrm{R}$ and about $30 \mathrm{~ms}$ in model $\mathrm{N}$ at an extreme uptake of $100 \mu \mathrm{M} / \mathrm{s}$ (Fig. 7). In fact, the delay is a pseudo-delay because the initial values of $\mathrm{FAR}^{\prime}$ directly after stimulus onset are just too small to be visible. They are, however, large enough to elicit a receptor-potential. The latter starts with a much smaller delay of about $10 \mathrm{~ms}$ (Fig. 7a, b) which corresponds to the smallest delay measured in A. polyphemus (Fig. 7b in Kaissling 2001). The delay of the model receptor-potential almost disappears if diffusion is made infinitely fast (Fig. 7c, d). With infinitely fast diffusion, the pseudo-delay of $F A R^{\prime}$ is shorter and its rise is faster; the remaining time course of $F A R^{\prime}$ is solely due to the chemical reactions of the network.

The saturation kinetics of $F A R^{\prime}$ and the receptor potential reveal marked differences between the models. During extremely strong stimuli, the active pheromone complexes FA and FB accumulate and need extra time for their deactivation. For a given stimulus load, e.g. $1 \mathrm{mM}$ for $2 \mathrm{~s}$, the fall of $F A R^{\prime}$ is delayed in models $\mathrm{N}$ and $\mathrm{R}$ for more than $60 \mathrm{~s}$ (Fig. 8a, b, asterisks), while the delay is hardly visible in model $\mathrm{S}$ (Fig. 8c, asterisks). The differences are reflected in the model receptor potentials (Fig. 8, dots). Since pronounced delays were already observed in receptor potentials or electroantennograms recorded at much lower stimulus loads (Kaissling 1971, 1972, 2001) model S seems less likely. Thus, we tentatively conclude that the deactivation is a process catalyzed by $\mathrm{N}$ or $\mathrm{R}$.
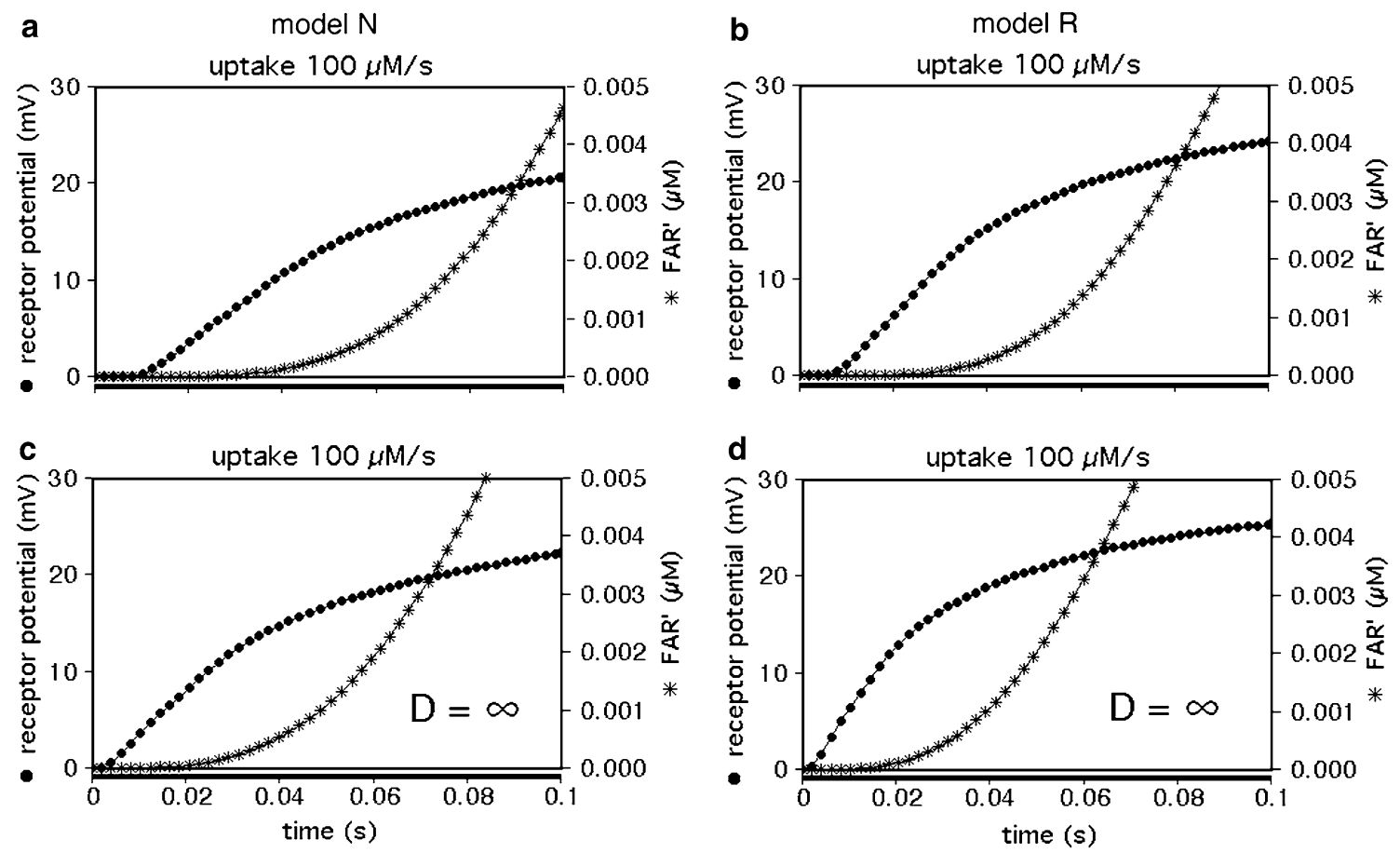

Fig. 7 Initial increase of $F A R^{\prime}$ and simulated receptor-potentials for 0.1 -s stimuli at high uptake. Modelling includes diffusion of the pheromone molecules $(\mathbf{a}, \mathbf{b})$. The initial delay of the simulated

receptor-potential of about $10 \mathrm{~ms}$ corresponds to the measured delay (Fig. 7b in Kaissling 2001). It almost disappears with infinitely fast diffusion (c, d) while the rise of FAR' is speeded up by about $10 \mathrm{~ms}$ 


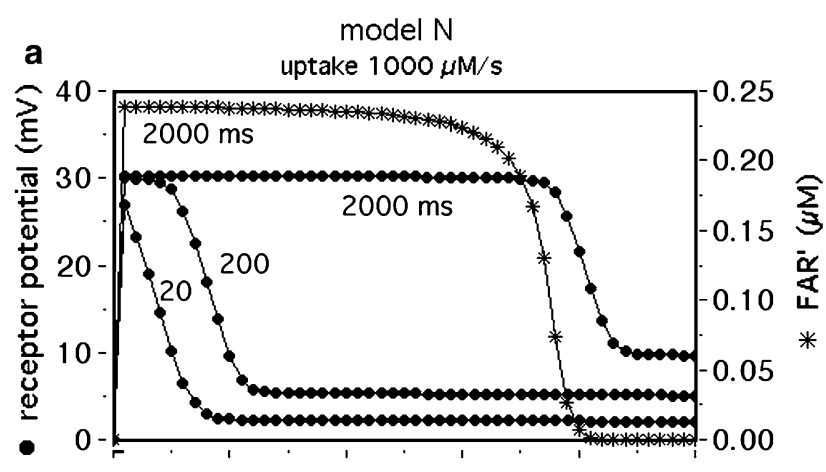

b

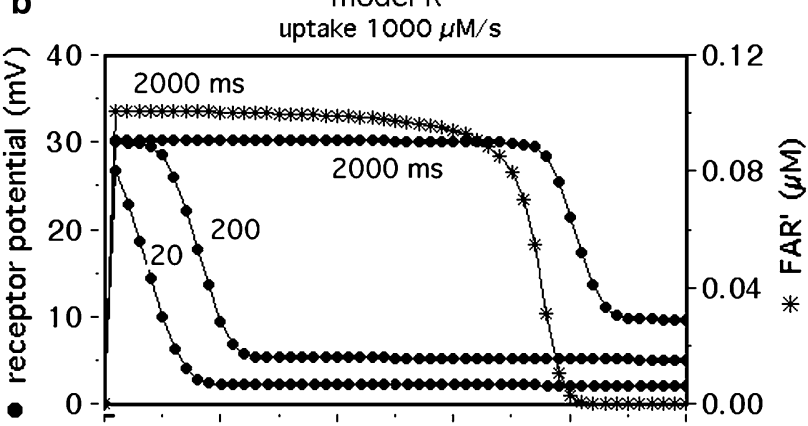

c

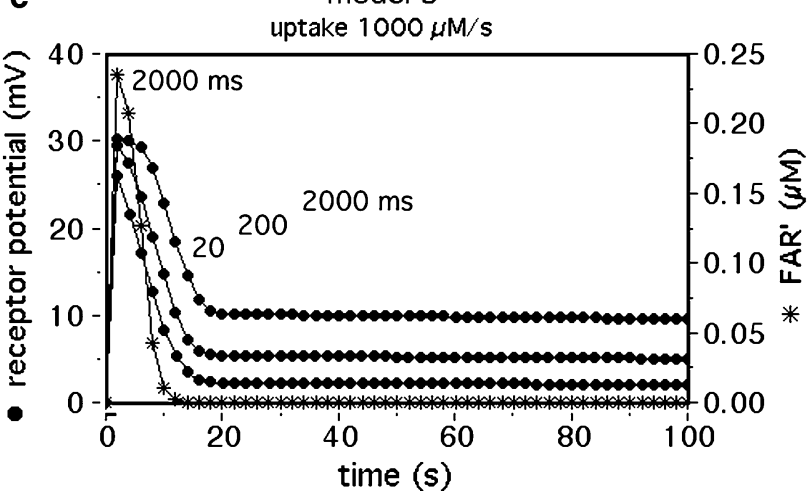

Fig. 8 Delayed fall of $\mathrm{FAR}^{\prime}$ and the receptor potential, due to overloading of the deactivation mechanism at stimuli above $U_{\text {sat }}$. Time course of simulated receptor-potentials with stimulus durations of 20,200, and 2,000 ms. The time course of $F A R^{\prime}$ is shown for $2,000 \mathrm{~ms}$ stimuli only. Model N (a) and model R (b) show similar delays. The delay produced by model $\mathrm{S}(\mathbf{c})$ is much smaller indicating a higher capacity of deactivation

Simulating the receptor potential

We simulate the transients of the receptor potential measured in A. polyphemus (Fig. 9c-f) using the assumption of very fast intracellular signalling. We assume that stimulusinduced changes of the receptor-potential amplitude almost instantly follow the changes of the FAR' concentration. To each value of $F A R^{\prime}$ the computer program (designed by $\mathrm{J}$. Thorson, see Kaissling 2001) assigns a mV-value, taken from the steady relationship of $F A R^{\prime}$ and the measured receptor-potential ( $F A R^{\prime}-\mathrm{mV}$ conversion). By this method the computer program converts the time course of $F A R^{\prime}$ to the one of a model receptor-potential (Fig. 6c) and finds out the half-times of rise and fall.

Firstly, we describe the simulation with $t_{1 / 2 F A R^{\prime} \text { fall }}=$ $0.8 \mathrm{~s}$ adjusted at $10^{-2} \mu \mathrm{M} / \mathrm{s}$ (see Appendix A, $k_{\text {fall }}$ ). While at uptakes up to $1 \mu \mathrm{M} / \mathrm{s}$ the transients of $F A R^{\prime}$ after stimulus onset and offset proceed with almost similar velocity (Fig. 1b, c), the predicted receptor potential shows the typical asymmetry of the measured receptor potential. It rises relatively rapidly, with half-times from $400 \mathrm{~ms}$ down to less than $50 \mathrm{~ms}$ (Fig. 9c), and falls much more slowly, with half-times of 1.5-10 s and more (Fig. 9b). The faster rise of the model receptor-potential as compared with the rise of FAR' is also demonstrated in Fig. 7.

While $F A R^{\prime}$ rises with a constant half-time over a wide range of uptakes, the rise times of the model receptorpotentials decrease with higher uptakes, over the entire range of uptakes. This fits to the measured rise times (Fig. 9c). Model N produces half-times up to $100 \mathrm{~ms}$ larger than model $\mathrm{R}$.

The model half-times of the fall of the receptor-potential amplitude (Fig. 9c, d) agree with the data-at uptakes below the "adjustment uptake" $\left(10^{-2} \mu \mathrm{M} / \mathrm{s}\right.$, Fig. 1b). At higher uptakes, however, the fall times of the simulated receptor-potential are much (up to about 50\%) smaller than those of the measured receptor potential. This discrepancy almost disappears if we use-instead of the adjusted $t_{1 / 2 F_{A} \text { fall }}=0.8 \mathrm{~s}$ of the chemical model-the experimental values of $t_{1 / 2 F A R^{\prime} \text { fall }}$ of $0.5-2 \mathrm{~s}$ (Fig. 1b). Using the latter, however, strongly impairs the simulation of the rise times (Fig. 9c, double circles).

The typical tailing (Fig. 8) was observed in recorded receptor-potentials at high stimulus uptakes (Kaissling 1998a, b, Figs. 5, 8). As shown in Kaissling (2001), the tailing of the model response disappears with $k_{13}=0$. Therefore, tailing could indicate a minimal dissociation of the intact pheromone $(\mathrm{F})$ from the deactivated complex (FB*) (reaction 13).

Varying model parameters

\section{Varying the concentration of the PBP}

Diminishing $A_{\text {tot }}$ shifts all dose-response curves along the $x$-axis to higher uptakes: for a given uptake we find smaller steady amplitudes, faster fall and slower rise of the receptor potential (Fig. 10). According to the model (Eq. 41), at smaller $A_{\text {tot }}$ a smaller percentage $\left(Q_{1}\right)$ of the incoming stimulus molecules will be bound to the PBP. Thus a smaller $A_{\text {tot }}$ means a weaker protection from enzymatic degradation and, consequently, smaller stimulus intensity. The effects of decreasing $A_{\text {tot }}$ are small if compared with 

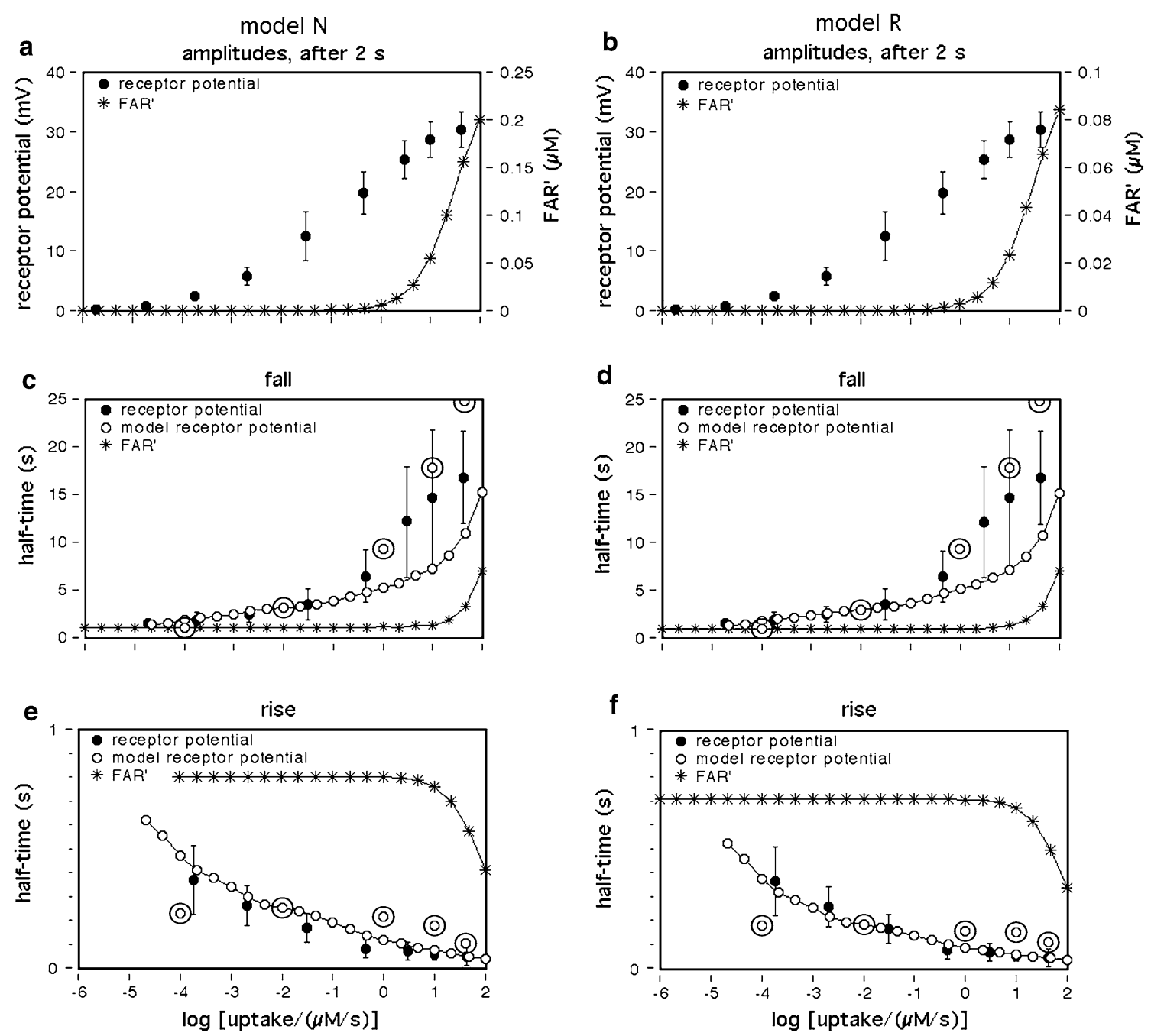

Fig. 9 Dose-response functions of $F A R^{\prime}(\mathbf{a}-\mathbf{f})$ and the simulated receptor-potential transients $(\mathbf{c}-\mathbf{f})$. For the experimental data (dots) see legend Fig. 1. The simulation (c-f) results from the $F A R^{\prime}-\mathrm{mV}$ conversion (see "Simulating the receptor potential"). Double circles

varying uptake (Fig. 11a-d). The opposite effects found upon increasing $A_{\text {tot }}$ are minimal.

Results similar to those described for varying $A_{\text {tot }}$ may be obtained by varying $k_{2}$ (Figs. $10,11 \mathrm{c}, \mathrm{d}$ ). A decrease of the dissociation rate constants $k_{-2}$ and $k_{-3}$ has no effect. Their increase up to factor of one hundred has hardly visible effects (not shown).

\section{Varying pheromone degradation and deactivation}

Removing the pheromone-degrading enzyme has almost no effect on the receptor potential (Fig. 11e, f), whereas the deactivation process strongly affects the transients of the receptor potential (Fig. 11i-l). Interestingly, models $\mathrm{N}$ and $\mathrm{R}$ may differ in their responses to alterations of a specific parameter (cf. Fig. 11i, j, or k, l). For instance, the alteration of $k_{8 N}$ in model $\mathrm{N}$ affects the fall of the receptor-

receptor-potential simulation using the experimental half-times of the fall of $F A R^{\prime}$ (see Fig. 1b). This simulates the fall of the receptor potential more exactly, while its rise is better matched by using the adjusted half-time $(0.8 \mathrm{~s})$ of the fall of $F A R^{\prime}$ (single circles)

potential strongly, but its amplitude only little (Fig. 11k). In contrast, $k_{8 R}$ in model $\mathrm{R}$ strongly affects the amplitude, but to a smaller extent the fall (Fig. 111).

\section{The chemical specificity of the receptor-neuron response}

In principle, several model parameters may contribute to the chemical specificity of the receptor-neuron response. The examples given here show that alteration of a given model parameter may cause different effects depending on the type of model. Varying the rate constant $k_{4}$ causes similar but also opposite effects in the two models. A smaller $k_{4}$ depresses the steady amplitude (after $2 \mathrm{~s}$ stimulation) in both models. It accelerates, however, the fall after stimulus offset in model $\mathrm{N}$, but slows down the fall in model R (Fig. 11g, h). Similar differences between the models are seen with varying $k_{5}$ and $R_{\text {tot }}$ (Fig. $11 \mathrm{i}, \mathrm{j}$ ). 
model $\mathrm{N}$
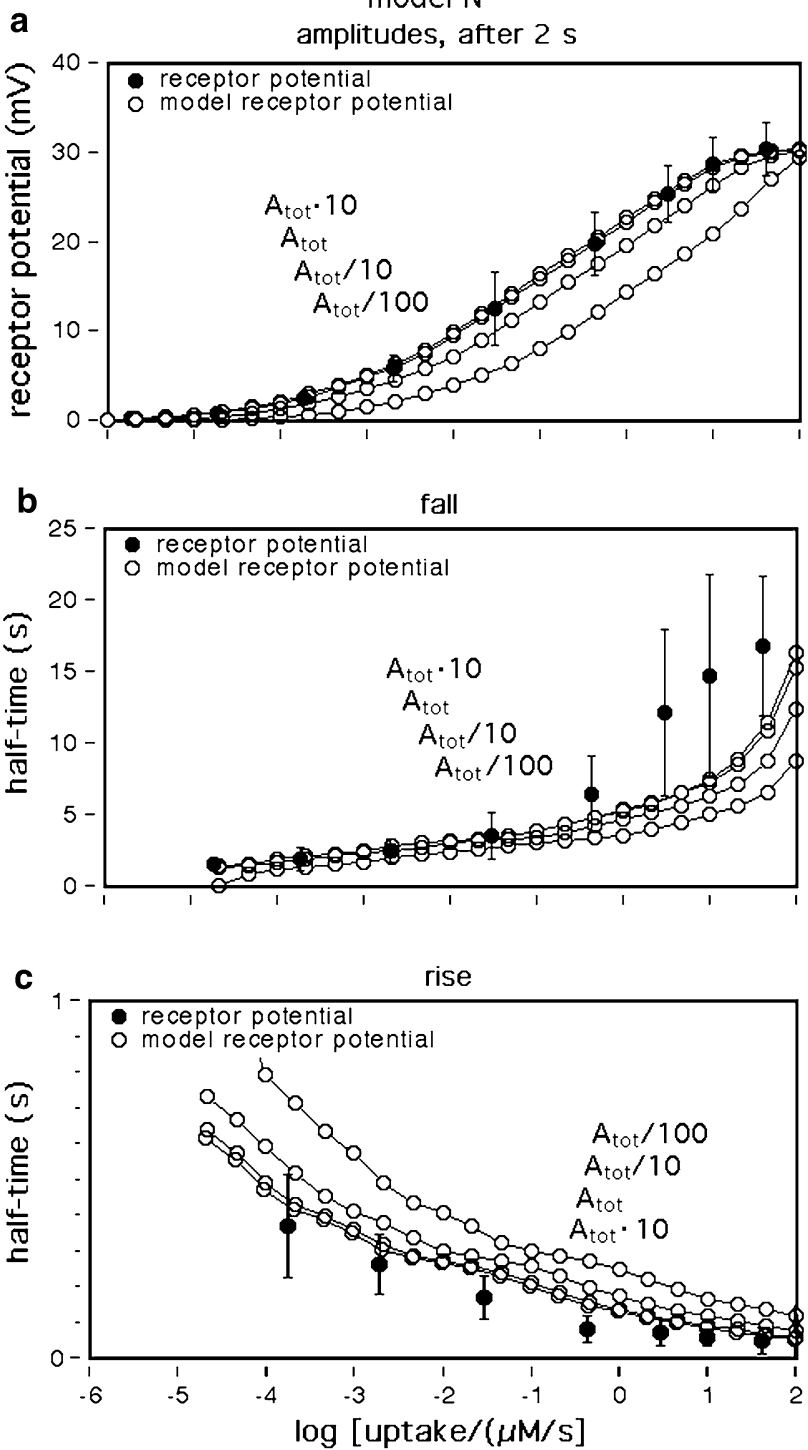

Fig. 10 Dose-response functions obtained by varying the PBP concentration $A_{\text {tot }}$, model N. Dots experimental data (see legend Fig. 1a). Decreasing PBP concentrations $\left(A_{\text {tot }} / 10, A_{\text {tot }} / 100\right)$ shift the dose-response curves to higher uptake values. This leads to smaller steady amplitudes (a), faster fall (b), and slower rise of the receptorpotential (c). Interestingly, an increase of the PBP concentration $\left(A_{\text {tot }} 10\right)$ has minimal effects, suggesting that the natural PBP concentration $\left(A_{\text {tot }}\right)$ is almost optimal

Stimulus compounds that are less effective than the key compound may (1) shift the three dose-response curves (of the steady amplitude of the receptor-potential, of the halftimes of rise and fall) along the $x$-axis to higher uptake values. In addition, the steady amplitudes may (2) reach a smaller maximum. Interestingly, the steady dose-response curve may (3) increase over a narrower range of uptakes. All of these effects may be produced by the same model parameter, e.g. by an increase of $k_{-6}$ that determines the duration of a single receptor molecule activation (Fig. 12).
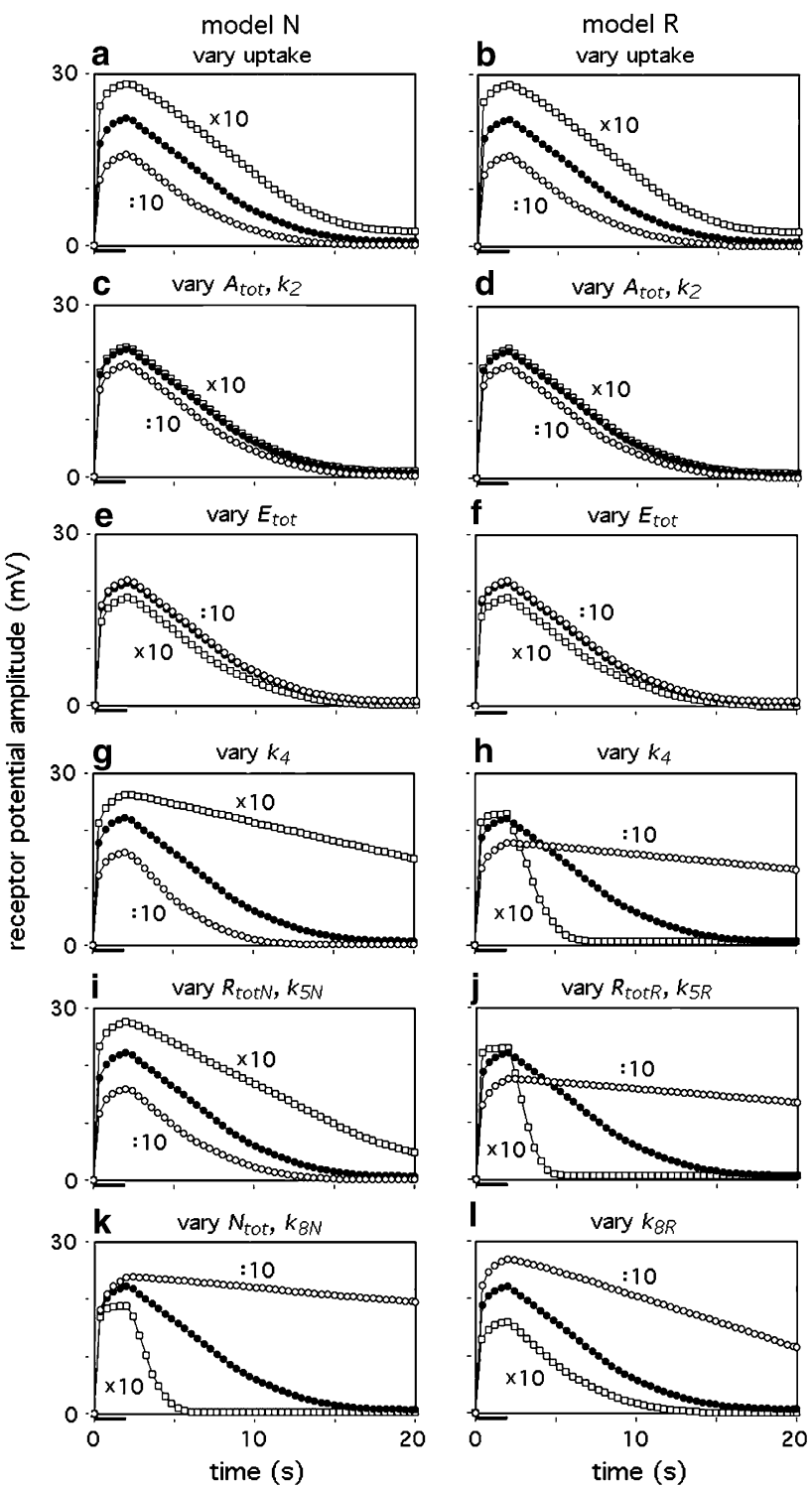

Fig. 11 Receptor potentials generated with model parameters varied by the factor 10 up (squares) and down (circles). In $\mathbf{a}$ and $\mathbf{b}$ the uptake was varied around $1 \mu \mathrm{M} / \mathrm{s}$ (dots), it was always $1 \mu \mathrm{M} / \mathrm{s}$ in $\mathbf{c}-\mathbf{l}$. The stimulus duration was $2 \mathrm{~s}$. The models $\mathrm{N}$ and $\mathrm{R}$ may respond differently to variation of a specific parameter. In some cases two parameters are specified if their variations produced indistinguishable effects

\section{Discussion}

The chemical model of perireceptor and receptor events together with the assumption of relatively fast intracellular signalling describe the kinetics of the receptor potential sufficiently well except for its fall at very high-stimulus uptakes. The results of modelling agree with all experimental findings. This supports the importance in vivo of the pheromone protection from degradation and of the pheromone deactivation postulated in addition to degradation. 

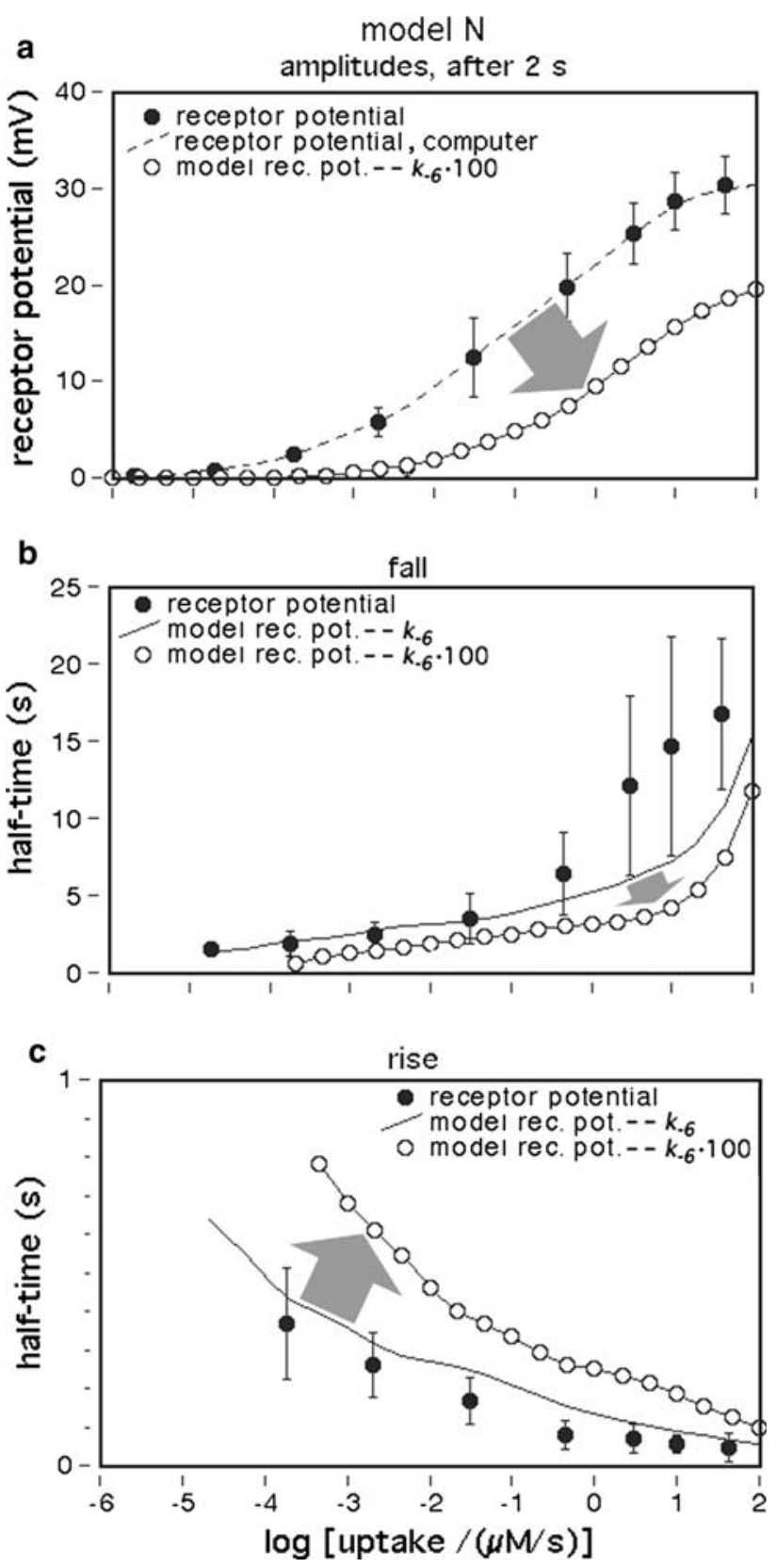

Fig. 12 Dose-response functions after alteration of a single parameter, $k_{-6}$. The steady dose-response curve is shifted to higher uptakes, the saturation amplitude is reduced and the curve increases over a narrower range of uptakes (a). The fall of the model receptorpotential becomes faster (b), whereas its rise slows down (c). The changes are indicated by arrows. Dots experimental data (see legend Fig. 1a). The dashed line in (a) shows the adjusted computer reference of the data

The roles of the PBP

There is experimental and model evidence for at least four functions of the PBP. The PBP (1) solubilizes and transports the pheromone, (2) it protects the pheromone from enzymatic degradation, (3) in vivo the pheromone interacts with the receptor molecules while bound to the PBP and (4) the PBP is most likely involved in the postulated odorant deactivation. Finally, this protein serves as an organic anion, with a surplus of nine negative charges per protein molecule. The PBP compensates for the lack of anions found by elementary analysis of the sensillum lymph (Kaissling and Thorson 1980).

The model concentration of the PBP $\left(A_{\text {tot }}\right)$ was indirectly determined using Eq. 41 based on the assumption that the pheromone after adsorption has two options. Its fraction $1-Q_{1}$ encounters the pheromone-degrading enzyme E, while its fraction $Q_{1}$ binds to the PBP and is protected from enzymatic degradation. The calculated $A_{\text {tot }}=3.8 \mathrm{mM}$ (or $3.2 \mathrm{mM}$, Appendix A) is astonishingly close to the range directly determined in the moth $A$. polyphemus (5-10 mM) (Vogt et al. 1985; Vogt and Riddiford 1986; Klein 1987). This agreement supports the above assumption of two options. It excludes the previously discussed third possibility that much of the adsorbed pheromone disappears, i.e. becomes lost in a cuticular compartment (Vogt 1987).

By varying the model concentration of the PBP $\left(A_{\text {tot }}\right)$ it could be shown that an increase of the in vivo concentration would not provide higher steady amplitudes and a more rapid rise of the receptor-potential, and, consequently, not improve sensitivity and temporal resolution of the responses. It is, however, still unclear why the natural PBP concentrations strongly vary, e.g. in cases where several PBPs occur in the same sensilla. Thus, PBP1:PBP2:PBP3 in male moths of A. polyphemus were found in the proportions 70: $<1: 30$ and in Antheraea pernyi in the proportions 50:50: $<1$, respectively (Maida et al. 2003). Each of the three PBPs binds best one of three pheromone components (compounds 1-3) detected by three cell types that coexist in the same sensilla. Compound 1, the best ligand of PBP1, is the major pheromone component of $A$. polyphemus and compound 2, the best ligand of PBP2, is the major pheromone component of $A$. pernyi. Except for the PBP of $B$. mori the dissociation constants of the PBPs and their pheromone components are unknown.

In male moths of $B$. mori, each sensillum trichodeum has one receptor neuron for bombykol and one for bombykal (Kaissling et al. 1978). Only one PBP has been found binding bombykol (Maida and Pelosi 1989; Maida et al. 1993, 2005). It mediated cell responses to bombykol only (Pophof 2004; Grosse-Wilde et al. 2006) although it also bound bombykal (after long-time incubation, Graeter et al. 2006; Zhou et al. 2009). There are further PBPs in Bombyx occurring in minute amounts (Maida et al. 1997; Forstner et al. 2006). 
Pheromone protection by pheromone-PBP binding

As shown here the high concentration of PBP in vivo may be necessary for rapid binding of the incoming pheromone and hence its protection from enzymatic degradation, on its way towards the receptor neuron. Protection is very effective although not complete; it is modelled by a 20,000 -fold smaller affinity of the enzyme $\mathrm{E}$ to the complex $\mathrm{FB}^{*}$ as compared with the affinity to the free pheromone.

The rapid formation of the complex $\mathrm{FB}$ at neutral $\mathrm{pH}$ rules out the previously proposed sequential model version in which the incoming pheromone first forms the complex $\mathrm{FA}_{1}$ (at the inner hair wall). Thereafter, $\mathrm{FA}_{1}$ changes to $\mathrm{FB}$ for transport, and finally $\mathrm{FB}$ turns into $\mathrm{FA}_{2}$ (at the receptorneuron) for the interaction with the receptor molecule (Kaissling and Leal 2004; Kaissling 2004; Lautenschlager et al. 2005). The reason to exclude this model version is that the rate constant $k_{3}$ of formation of FA is about tenfold smaller than $k_{2}$. The slow initial formation of $\mathrm{FA}_{1}$ in the sequential model would mean an impaired protection from pheromone degradation. This may be simulated by removing $k_{2}$ from Eq. 41. The calculation reveals $Q_{1}=0.32$, which means that $68 \%$ (instead of the measured $17 \%$ ) of the incoming pheromone would be lost. Therefore, in the network discussed here the complex FB is formed (reaction 2), in parallel to FA (reaction 3).

It seems counterintuitive that the association rate constant at neutral $\mathrm{pH}\left(k_{2}\right)$ is tenfold larger than at low $\mathrm{pH}\left(k_{3}\right)$, and that the dissociation rate constants $\left(k_{-2}\right.$ and $\left.k_{-3}\right)$ hardly depend on $\mathrm{pH}$ (Figs. 4, 5). At neutral $\mathrm{pH}$ the pheromone associating with the PBP A-form should need more time to displace the $\mathrm{C}$-terminus from the inner binding cavity and to induce the change of the A-form into the B-form. At low $\mathrm{pH}$, however, when the inner binding cavity is occupied by the C-terminus, the pheromone merely could bind to hydrophobic sites on the periphery of the PBP A-form.

Interestingly, bovine serum albumin was shown to be able to perform at least two functions of the PBP. The albumin solubilized the pheromone (Van den Berg and Ziegelberger 1991) and protected it from the enzymatic degradation (Vogt and Riddiford 1986), both as effectively as the PBP. It remains to be seen of whether the albumin also could fulfil other functions of the PBP as mediating the interaction with the receptor molecule or the pheromone deactivation.

Pheromone-PBP-receptor molecule interaction

A direct interaction of the free pheromone with the receptor molecules may be possible in experiments in which high pheromone concentrations were used (Syed et al. 2006). In experiments without the natural binding protein one should exclude that other proteins are present and replace its function. It seems clear, however, that in vivo, in the presence of PBP, the pheromone-PBP complex rather than the free pheromone $\mathrm{F}$ interacts with the receptor molecules. Modelling reveals that the concentration and life-time of the active complex FA are much larger than the one of the free pheromone $\mathrm{F}$ ( $>50$-fold and $>10$-fold, respectively, see Appendix A). Consequently, if F instead of FA interacts with the receptor molecules, it would constitute a very ineffective system.

As proposed previously (Kaissling 2001), the pheromone in the excitatory complex FA could be associated to hydrophobic patches on the outer side of the protein possibly facilitated by the dimeric structure of the PBP. That the PBP occurs as a dimer was suggested by Kaissling et al. (1985) and finally proven by Campanacci et al. (1999) and Leal (2000). Remarkably, binding to the surface of the Aform allows the pheromone to interact with the receptor molecule but protects it from the degrading enzyme.

Experiments in A. polyphemus with direct application of PBP and pheromone components during electrophysiological recordings support the idea that PBP is involved in the pheromone-receptor molecule interaction. The receptor-neuron, type 1 , tuned to the pheromone component 1 responded to the normally ineffective component 2 when the latter was offered together with PBP1. Obviously, the PBP1 mediated the interaction of neuron type 1 with the "wrong" pheromone component 2 (Pophof 2002, 2004). Applying the PBP of a different moth species (ApolPBP1 from A. polyphemus) in B. mori produced a response of the bombykol receptor-neuron even with no bombykol present (Pophof 2004). The bombykal receptor-neuron present in the same sensillum did not respond which supports the idea of a specific interaction between binding protein and receptor molecule.

The proposed mediator function of the PBP is supported by findings in Drosophila melanogaster. The pheromonebinding protein LUSH is required to activate receptorneurons by the pheromone (Z)-11-vaccenyl acetate $(\mathrm{Xu}$ et al. 2005). Recently, it was shown that the pheromone induces an activated conformation in the PBP, which is recognized by the neuronal receptor molecules (Laughlin et al. 2008). If this occurs also in Bombyx it would require two A-forms of the PBP, the inactive form (A) present in the absence of the pheromone and an active form induced by binding the pheromone $\left(\mathrm{FA}^{\prime}\right)$. In Drosophila, the $\mathrm{LUSH}^{\mathrm{D} 118 \mathrm{~A}}$ mutant simulating the structure of the active PBP activated the receptor neuron-in the absence of the pheromone (ibid.). For the response to $\mathrm{LUSH}^{\mathrm{D} 118 \mathrm{~A}}$ the neuronal receptor molecule Or67d and also sensory neuron membrane protein (SNMP) was necessary. 


\section{Model N or R?}

Models $\mathrm{R}$ and $\mathrm{N}$ have been introduced by Kaissling (1998a) and further discussed by Kaissling (1998b, 2001), respectively. Model $\mathrm{S}$ with spontaneous deactivation as a first-order process (Appendix B) may be ruled out because it does not appropriately simulate the pronounced saturation kinetics of the receptor potential (Fig. 8). Thus, the models $\mathrm{N}$ and $\mathrm{R}$ with enzymatic deactivation remain to be discussed. Both models are based on the special physiological quantities $U_{\text {sat }}(=30 \mu \mathrm{M} / \mathrm{s})$ and $k_{\text {fall }}(=0.87 / \mathrm{s})$. There are a few minor differences between the two models. Model $\mathrm{R}$ has fewer receptor molecules, but a larger $k_{5}$. In model $\mathrm{R}$ the receptor-potential rises faster due to a faster formation of the complex FAR. The rise times of the measured receptor-potential are simulated by model $\mathrm{R}$ slightly more exactly than by model N (Fig. 11c, d). Certainly a faster rise of the receptor-potential is useful to resolve repetitive stimuli of higher frequency which may be advantageous for orientation in a turbulent odour plume (Kaissling 1997). The differences in rise times, however, seem too small for favouring one of the models.

Model $\mathrm{R}$ is supported by recent studies showing that properties of the olfactory receptor-potential kinetics were transferred together with genes of receptor molecules expressed in an "empty" olfactory neuron (Dobritsa et al. 2003; Hallem et al. 2004; Syed et al. 2006).

Model N was preferred by Kaissling (2001) since the putative receptor molecule blocker decyl-thio-1,1,1-trifluoro-propanone (Pophof 1998; Pophof et al. 2000; Kaissling 2004) did not seem to interfere with the odorant deactivation. Thus, the application of this blocker produced smaller receptor-potentials but did not change the half-time of their fall after stimulus offset. These effects agree with model $\mathrm{N}$ if the blocker reduces $k_{5}$ or $R_{\text {tot }}$ (see Fig. 11i). In contrast, for model $\mathrm{R}$ a reduction of $k_{5}$ or $R_{\text {tot }}$ would slow down the fall of the potential (see Fig. 11j), but this has not been observed.

Another argument favouring model $\mathrm{N}$ can be found from the analysis of elementary receptor-potentials in B. mori. According to Minor and Kaissling (2003, their Eq. 10) the total lifetime of FAR and FAR' for model $\mathrm{N}$ is

$T_{c N}=\frac{1}{k_{-5}}+\frac{k_{6}}{k_{-5} \cdot k_{-6}}=\frac{1}{k_{-5} \cdot Q_{4}}=153 \mathrm{~ms}$

For model $\mathrm{R}$ the total lifetime would be

$$
T_{c R}=\frac{1}{\left(k_{-5}+k_{8 R}\right) Q_{4}}=24 \mathrm{~ms}
$$

Because the smaller value of $T_{c R}$ is not compatible with the measurements of Minor and Kaissling (2003), model R appears obsolete.
In conclusion, the arguments in favour of model $\mathrm{N}$ seem more convincing. It should be noted that the model $\mathrm{N}$ would work as well if the enzymes $\mathrm{N}$ and $\mathrm{E}$ are the same protein. It seems, however, unlikely that different tasks, such as the pheromone degradation $(\mathrm{F} \Rightarrow \mathrm{M})$ and the modification of the $\mathrm{PBP}\left(\mathrm{FB} \Rightarrow \mathrm{FB}^{*}\right)$ required for deactivation are done by the same enzyme.

\section{Deactivation mechanisms}

It is common to all three models discussed that the mechanism of deactivation must involve a modification of the PBP to the scavenger form $\mathrm{B}^{*}$ while the pheromone bound to $\mathrm{B}^{*}$ remains chemically intact. In the previous model N (Kaissling 2001), odorant deactivation was achieved by a transformation of the PBP molecule from a reduced "transport" form $\left(\mathrm{B}_{\mathrm{red}}\right)$ into an oxidized "scavenger" form $\left(\mathrm{B}_{\mathrm{ox}}\right)$. This mechanism was suggested by the apparent redox shift of the pheromone-PBP complex observed in vitro (Ziegelberger 1995). The redox shift was shown to occur in the presence of a catalyst contained within the olfactory hairs, represented in our models by the hypothetical enzyme $(\mathrm{N})$ or the receptor molecules $(\mathrm{R})$. The redox-shift became questionable when Leal (2003) did not find the expected reduction of mass units. A final judgement about this phenomenon appears premature because there is other experimental evidence in favour of a redox shift (Ziegelberger 1995). In the present paper we leave the redox shift aside but keep hold of the models $\mathrm{N}$ and $\mathrm{R}$, with the deactivated (or scavenger) form $\left(\mathrm{B}^{*}\right)$ of the PBP.

A possible mechanism of forming a scavenger PBP (form $\mathrm{B}^{*}$ ) may be proposed for model N. In this model the postulated enzyme $\mathrm{N}$ is able to distinguish between the pheromone-PBP complex FA and those PBP molecules carrying a stimulus molecule inside the inner binding cavity, the complex FB. We propose-as a result of a discussion with F. Damberger and W. Leal-that the enzyme $\mathrm{N}$ might be able to recognize the exposed hydrophobic C-terminal tail of the B-form and to discriminate it from the exposed hydrophilic N-terminal tail of the Aform. The enzyme $\mathrm{N}$ could remove or block the C-terminal tail of FB and thus prevent FA from being formed.

This idea is supported by experimental removal of the $\mathrm{C}$ terminus, which eliminated the $\mathrm{FB} \Rightarrow \mathrm{FA}$ transformation at low $\mathrm{pH}$. The pheromone was irreversibly locked inside the binding cavity of the truncated PBP (Leal et al. 2005a). This way the pheromone could be made "invisible" to the receptor molecule. Furthermore, the PBP-pheromone binding at low $\mathrm{pH}$ was maintained by one-point mutation of the C-terminus (Xu and Leal 2008). Apparently, the formation of a C-terminal alpha-helix-necessary for the 
repulsion of the pheromone from the inner binding cavitywas blocked.

Numbers of receptor molecules, ion channels and SNMP

Combining Eqs. 25 and 52 reveals the most general equation for calculating the fictive concentration of receptor molecules $R_{\text {tot }}$ of a flux detector (see "Description of the models")

$R_{\mathrm{tot} N}=\frac{T_{c N} U_{\mathrm{sat}} Q_{3}}{Q_{5}}$

for model $\mathrm{N}$, with the total life-time $T_{c N}$ of the complexes FAR and FAR'. In the respective equation for model $\mathrm{R}$ the term $Q_{5}$ needs to be replaced by $Q_{7}$. For a rough calculation of the density of receptor molecules, $T_{c N}$ and $Q_{5}$ were taken from the bombykal receptor neuron of B. mori, $Q_{3}$ was measured for the bombykol receptor neuron, and $U_{\text {sat }}$ was determined for the main pheromone of A. polyphemus, with $Q_{3}=0.25$ and $U_{\text {sat }}=30 \mu \mathrm{M} / \mathrm{s}$ as minimum values (Appendix A). Our best guess is that the densities of olfactory receptor molecules are in a range about tenfold smaller than a theoretical maximum represented by the density of rhodopsin in the in the outer disc membrane of vertebrate visual cells $\left(40,000 / \mu \mathrm{m}^{2}\right.$, Dratz and Hargrave 1983). The number of receptor molecules estimated per neuron for the main pheromone of $A$. polyphemus amounts to 2.6 million and to a tenfold smaller number for the bombykal neuron in B. mori.

The estimated densities of olfactory receptor molecules are by far higher than the presumed density of ion channels in the plasma membrane of the olfactory receptor-neuron. Attempts to estimate the latter revealed a minimum of 10,000 ion channels per receptor neuron of A. polyphemus with a conductance per channel of $30 \mathrm{pS}$ (Kaissling and Thorson 1980). This corresponds to a channel density of 23 per $\mu \mathrm{m}^{2}$ and fits to the number of about 20 putative ion channels per $\mu \mathrm{m}^{2}$ estimated from atomic-force microscopy of dendritic membranes (Kaissling and Kumar 1997; Eschrich et al. 1998).

Thus, the numbers of receptor molecules per ion channel would amount to roughly $4,000 / 20=200$. This ratio would imply a large average distance between receptor molecules and ion channels, much higher than expected from a direct coupling of receptor molecules and adjacent ion channels. From geometrical reasons, for direct coupling a ratio below ten receptor molecules per ion channel seems more likely (Wicher et al. 2008; Sato et al. 2008). This small ratio could be reached either by a smaller number of receptor molecules, or a larger number of ion channels, perhaps with a smaller conductance per channel. The large numbers of receptor molecules are required for the wide range of stimulus intensities covered by the dose-response curves of the receptor-potential.

Recently it has been found in Drosophila that the receptor molecules are associated with the SNMP (Benton et al. 2007) and that this protein is required for pheromone sensitivity (Jin et al. 2008). The density of SNMP molecules may be roughly estimated from electron-micrographs showing gold-labelled antibodies against SNMP in olfactory sensilla of $A$. polyphemus. From the micrographs in Rogers et al. (2001) 300 gold particles $/ \mu \mathrm{m}^{2}$ of the membrane of pheromone receptor-neurons may be counted. This figure corresponds to a minimum of about $5 \%$ of the density of receptor molecules in A. polyphemus calculated for model N. The density of SNMP could, however, well be higher if only a small fraction of the SNMP molecules carried a gold particle.

$\mathrm{EC}_{50}$ of the pheromone-receptor molecule interaction

Nakagawa et al. (2005) determined the $\mathrm{EC}_{50}=1.5 \mu \mathrm{M}$ for bombykol and the heterologously expressed bombykol receptor molecule. The $\mathrm{EC}_{50}$ provides a maximum estimate of the dissociation constant of the pheromone and receptor molecule interaction and may be compared with the model $\mathrm{EC}_{50}$ of the complex FA and the receptor molecule. For both models we find $\mathrm{EC}_{50}=6.8 \mu \mathrm{M}\left(\mathrm{EC}_{50}=K_{\mathrm{d} 5 N} Q_{4}\right.$ for model $\mathrm{N}$, or $\mathrm{EC}_{50}=K_{\mathrm{m} 5,8} Q_{4}$ for model R). Considering that our model uses data from two species of moths, and it yields an $\mathrm{EC}_{50}$ for binding the pheromone-PBP complex rather than the free pheromone, a closer agreement with the results of Nakagawa et al. is not expected.

\section{Receptor-potential transients}

The receptor-potential kinetics differs from the one of $F A R^{\prime}$ because it depends - in addition to $F A R^{\prime}$ — on other factors such as the electrical circuit of the sensillum and on intracellular transduction processes. While in models $\mathrm{N}$ and $\mathrm{R}$ the steady $\mathrm{FAR}^{\prime}$ concentration rises in linear proportion to the uptake, the dependence of the "steady" amplitude of the receptor-potential on the uptake-and on FAR' -is highly nonlinear (Fig. 1a).

For our simulation of the receptor-potential transients, we used the method of $\mathrm{FAR}^{\prime}-\mathrm{mV}$ conversion. The underlying assumption of very fast intracellular signalling is supported by the recent analysis of Gu et al. (2009). For a theoretical, stepwise onset of $F A R^{\prime}$ they found that the halftime of the rise of the receptor-potential would be $16 \mathrm{~ms}$ only. Our measured half-times were much longer, $400 \mathrm{~ms}$ at weak, and $50 \mathrm{~ms}$ at strong stimulation (Fig. 11e, f). The half-time of the receptor-potential fall would be-according to these authors-about $1 \mathrm{~s}$ at weak and $2.2 \mathrm{~s}$ at strong stimulation, whereas the measured half-time in 
A. polyphemus was 1.5 and $17 \mathrm{~s}$, respectively (Fig. 9c, d). A fast signalling may also be expected from the direct coupling of receptor molecules and ion channels (Wicher et al. 2008; Sato et al. 2008). Thus, our assumption of fast intracellular signalling seems to be correct and justifies our method of simulating receptor potential by the $\mathrm{FAR}^{\prime}-\mathrm{mV}$ conversion (see "Simulating the receptor potential").

As described in "Results", the simulation of the rise of the receptor-potential was satisfactory if we use the chemical model with the adjusted value of $t_{1 / 2 F A R^{\prime} \text { fall }}=0.8 \mathrm{~s}$, the half-time of the fall of $F A R^{\prime}$, the concentration of activated receptor molecules. The simulation of the fall of $F A R^{\prime}$ was, however, incorrect at higher stimulus uptakes. This discrepancy was shown to be due to the measured increase of $t_{1 / 2 F A R^{\prime} \text { fall }}$ occurring at uptakes far below saturation (Kaissling 1998b; Fig. 1b). Since the increase of $t_{1 / 2 F A R^{\prime} \text { fall }}$ is not explained by the chemical model, we conclude that it is due to intracellular processes developing during the $2 \mathrm{~s}$ of stimulation. The rise of the receptor potential, however, is apparently governed by the extracellular processes. Besides the measured values of $t_{1 / 2 F A R^{\prime} \text { fall }}$ of $0.5-2 \mathrm{~s}$ for A. polyphemus there is available only the value of $0.34 \mathrm{~s}$ estimated for a receptor-neuron of $B$. mori very weakly stimulated with bombykal (Fig. 23 in Kaissling 1987).

In our models the delayed fall of $F A R^{\prime}$ and the receptorpotential after offset of strong stimuli (near to, or above $\left.U_{\text {sat }}\right)$ is due to a saturation of the deactivation mechanism causing accumulation of mainly FB and the active stimulus complex FA within the sensillum. The delayed fall of the receptor potential has been frequently observed in pheromone-receptor neurons (Kaissling 1971, 1987, 2001). As shown by Kaissling (1971), the delayed fall even occurs with pheromone derivatives that produce smaller maximum receptor-potential amplitudes than the pheromone. Smaller maximum amplitudes of the receptor potential may be produced by the chemical model, e.g. if the pheromone derivative induces a smaller activation of the receptor molecule by an increased rate constant $k_{-6}$.

The tailing of the receptor potential after offset of strong stimuli disappears if reaction 13 is omitted. This suggests that deactivation is, to some degree, reversible, and that stimulus molecules may activate receptor molecules for a second time.

In summary, the simulation shows that the saturation effects and the tailing of the response may be produced by perireceptor events.

The shallow dose-response curve

The asymmetric shape, i.e. the fast rise and the much slower fall of the receptor potential, is a consequence of the nonlinear slope of the steady dose-response curve covering a range of stimulus intensities much wider than covered by the standard hyperbolic binding or logistic curve. Part of the shallow slope may be due to shortening the electrical length constant of a long dendrite with increasing stimulation and increasing electrical membrane conductance of the neuron (Kaissling 1971; Vermeulen et al. 1997). As suggested by Gu et al. (2009) this slope may in addition be produced, if elements of the intracellular signalling cascade or specific types of ion channels become active at different stimulus intensities.

An additional explanation so far not considered is the varying effectiveness of molecule capture along the length of the olfactory hairs. Thus, the distal half of the long hairs of A. polyphemus caught $70 \%$ of the radiolabeled pheromone molecules caught by the entire hairs (Kanaujia and Kaissling 1985). This could mean that receptor molecules located near the hair base receive far fewer stimulus molecules than those near the hair tip.

Furthermore, the sensitivity of the receptor neuron may differ depending on the locus of stimulation along the hair. Figure 13 shows an example demonstrating that

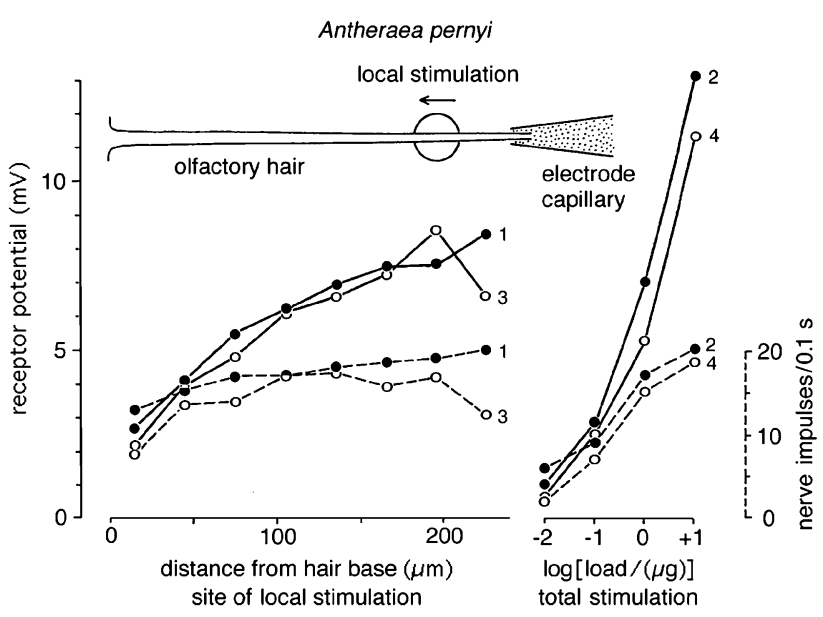

Fig. 13 Longitudinal response profile of an individual receptorneuron innervating a sensillum trichodeum of a male antenna of Antheraea pernyi. Plotted are the amplitudes of the receptorpotentials reached after $100 \mathrm{~ms}(\mathrm{mV}$, lines), and the numbers of nerve impulses (dashed lines) fired within $100 \mathrm{~ms}$. Local stimulation by $100-\mathrm{ms}$ air puffs delivered from a glass capillary of $30 \mu \mathrm{m}$ diameter (big circle) loaded with the main pheromone component (E,Z)-6,11-hexadecadienal. Two series of eight puffs (series 1, dots, and series 3 , circles) released from the same capillary were applied with $30 \mathrm{~s}$ intervals between puffs, with the capillary positions moved from tip to base of the hair (technique of local stimulation see Kaissling 1995). After each series of local stimulations, series of four puffs from $7 \mathrm{~mm}$ wide glass cartridges loaded with increasing amounts of pheromone ( $\mu \mathrm{g} /$ filter paper) were applied to the total antenna in order to determine dose-response curves (series 2, dots, and series 4 , circles). Comparing the local responses with the doseresponse curves it can be estimated that the sensitivity of the receptorneuron at the hair base was only $5 \%$ of the one at the hair tip. The slightly weaker responses of the series 3 and 4 as compared with 1 and 2 , respectively, might be ascribed to a fatigue of the stimulus sources or of the neuron. See discussion, "The shallow dose-response curve" 
stimulation of the hair tip produced much larger receptor potentials than stimulation of the hair base. In a few cases it could be observed that the sensitivity profile along the hair reversed during the course of the experiment. Often the base was found to be more sensitive than the tip (Kaissling 1995). In any case, a distributed molecule capture and/or sensitivity widens the working range of the receptorneuron.

The chemical specificity of the receptor-neuron response

Certainly a specific detector must be bound to each receptor neuron since usually two or more neurons tuned to different pheromone components innervate the same sensillum and share the same sensillum lymph space. For example, the receptor neuron of $B$. mori tuned to bombykol responds to bombykal if the latter is offered at a 10,000- to 100,000-fold higher concentration (Kaissling et al. 1978). As shown in "Results" several model reactions may contribute to the specificity of the receptor-neuron response. The alteration of a single model parameter such as an increase of $k_{-6}$ may strongly change the receptor-potential kinetics. In fact, the described alterations of the steady dose-response curve upon stimulation with pheromone derivatives (Fig. 12) were observed together with an additional effect: a smoother, less fluctuating time course of the receptor potential (Kaissling 1974, 1977, 1987, 1998a). The latter effect may as well be explained by an increased $k_{-6}$. With a larger $k_{-6}$, the single receptor molecule activations-reflected by the elementary receptor potentials ("bumps") — last a smaller time, too small to be resolved due to low-pass filtering by capacitances of the sensillum circuit (Kaissling and Thorson 1980; Minor and Kaissling 2003). The example of varying $k_{-6}$ supports the assumption that the specificity of the receptor-neuron response largely depends on the specificity of the stimulusreceptor molecule interaction, more on receptor activation rather than binding alone. It should be noted that adaptation after strong stimuli may cause similar alterations of the steady dose-response curves (Zack 1979; Kaissling 1987) as observed with pheromone derivatives (Fig. 12). This could indicate that adaptation affects the activation of the receptor molecule.

Our models show that interactions of the stimulus compound with extracellular proteins other than the receptor molecules, such as PBPs and enzymes, may contribute to the chemical specificity of the receptor-neuron response, but apparently to a smaller extent (Steinbrecht 1996). Varying $A_{\text {tot }}$ merely shifts the dose-response curves along the stimulus axis (Fig. 10). Thus, the specificity of the response might indeed depend more on the interaction with the receptor molecule than with the PBP even if the affinity to the receptor molecule is weaker than to the PBP $\left(K_{\mathrm{d} 5 N}>K_{\mathrm{d} 2}, K_{\mathrm{d} 30}\right)$. In vitro studies with isolated PBP and pheromone derivatives reveal that the specificity of binding to PBP is considerably smaller than of the neuron response, as, e.g. in A. polyphemus (De Kramer and Hemberger 1987; Meng et al. 1989; Prestwich et al. 1995; Oldham et al. 2000; Maida et al. 2003; Mohl et al. 2002), Lymantria dispar (Hansen 1984; Plettner et al. 2000; Kowcun et al. 2001), or B. mori (Zhou et al. 2009). The only case known so far of a noticeable specificity of pheromone-PBP binding is the major PBP of $B$. mori males which bound bombykol, but did not bind bombykal (A. Svatos, personal communication. Cf. "The roles of the PBP").

Almost no effects on the response are produced by altering the pheromone degrading enzyme. Removal of the pheromone degradation in the model, e.g. by using $E=0$, hardly changes the time course of the receptor-potential within a range of a few seconds after stimulation (Fig. 11e, f). This was concluded also from the finding that normal electrophysiological responses were recorded from antennae showing no activity of the pheromone degrading enzyme (Maida et al. 1995). Thus, it seems clear that the fall of the receptor potential after stimulus offset is not caused by pheromone degradation and that pheromone deactivation must occur.

Pheromone degradation seems to be little specific. Hexadecanol, a compound ineffective to the receptorneuron, and bombykol were enzymatically degraded in vivo with similar velocity (Kasang and Kaissling 1972). In vitro studies revealed little differences between the degradation of the pheromone component $(E, Z)-6,11$-hexadecadienyl acetate and 2-naphthyl acetate by the isolated sensillar esterase (Vogt et al. 1985).

An example of impaired enzymatic degradation might be the case of $(E, Z)-4,6$-hexadecadiene that produced almost normal receptor potentials if applied at concentrations about 100-fold higher than bombykol. The potential ceased after stimulus offset indicating the deactivation of the alkene. The nerve-impulse response, however, lasted for many minutes at a low level (Kaissling et al. 1989). This means that the deactivation did not completely remove the stimulant. Obviously, the alkene was not degraded by dehydrogenation as found for bombykol (Kasang et al. 1989b). This experiment shows the significance of enzymatic pheromone degradation: the total removal of active pheromone that is necessary to recover the high sensitivity of the receptor-neuron.

According to the model, stronger effects on the neuron response are expected from altering the hypothetical pheromone deactivation responsible for the fall of the receptor potential after stimulus offset (Fig. 11i). Pheromone deactivation, however, seems much less specific than the receptor-neuron response. The fall observed with less 
effective bombykol derivatives is sometimes slowed down, but for most test compounds accelerated. The half-life of the fall may be reduced to about $10 \%$ of the value with bombykol stimulation (Kaissling 1974, 1977, 1998a). As shown above, however, the fall may also depend on model parameters (e.g. $k_{-6}$ ) other than those of the deactivation process.

Summary of the temporal model characteristics

Taking together experimental data and modelling, we arrive at the following temporal characteristics. We calculate the average fictive half-lives of each model species for single reactions of model N (Fig. 14). After entering the hair lumen the free pheromone $\mathrm{F}$ has a half-life of about 3 ms due to binding to the PBP and the formation of FB (reaction 2). This half-life is even shorter than the one expected from enzymatic degradation (13 ms). Taking PBP binding and degradation together, the overall half-life of free pheromone is about $2 \mathrm{~ms}$ only. The direct formation of FA is comparatively slow (267 ms); actually FA is much more readily formed via FB (reactions 2 and 4). The formation of the activated receptor molecule $\mathrm{FAR}^{\prime}$ via the complexes FA and FAR is relatively slow, altogether in the

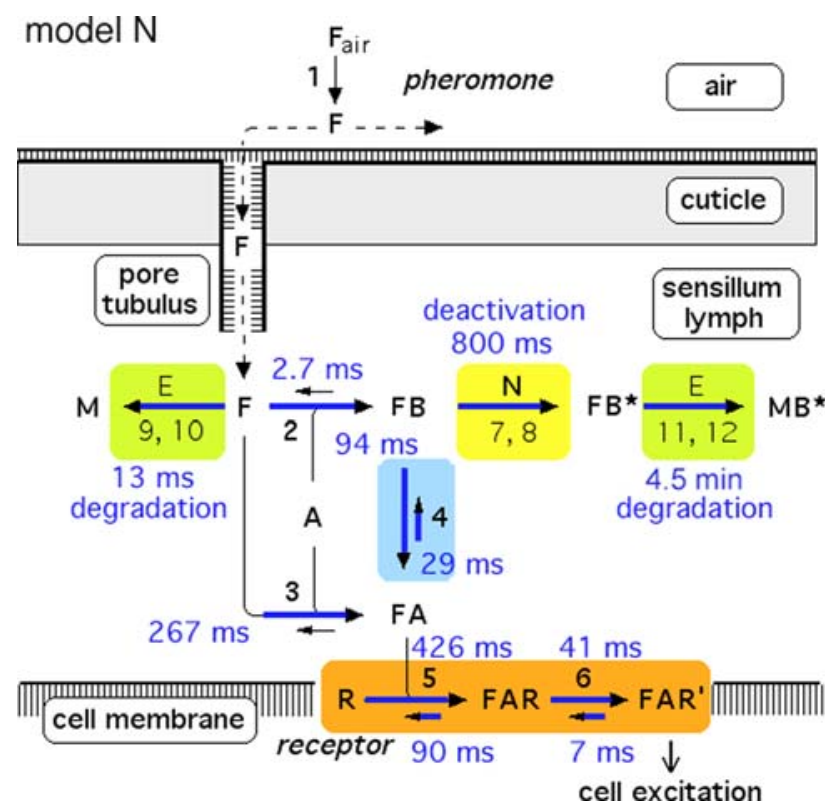

Fig. 14 Model $\mathrm{N}$ with the fictive half-lives of several model species calculated from the parameters of specific reactions (bold arrows). For example the half-life of $\mathrm{F}$ due to reaction 2 is $t_{1 / 2 F}=\ln 2 /$ $\left(k_{2} A_{\text {tot }}\right)=2.7 \mathrm{~ms}$, due to reaction 3 is $t_{1 / 2 F}=\ln 2 \quad \mathrm{C} /$ $\left(k_{3} A_{\mathrm{tot}}\right)=267 \mathrm{~ms}$, and due to reactions 9 and 10 is $t_{1 / 2 F}=\ln 2$ $K_{\mathrm{m} 9,10} /\left(k_{10} E_{\mathrm{tot}}\right)=13 \mathrm{~ms}$. The half-lives of $\mathrm{FB}$ and FA due to dissociation (reactions 2 and 3, small arrows) are 98 and $63 \mathrm{~s}$, respectively (not shown). See discussion, "Summary of the temporal model characteristics" range of about $400 \mathrm{~ms}$. This is close to the average reaction time of the nerve impulses fired after weak bombykol stimulation (about 200 ms, Kaissling and Priesner 1970; Kaissling 1987, 2009). The half-life of the activated pheromone-PBP-receptor molecule complex $\left(t_{1 / 2 F A R^{\prime} \text { fall }}\right)$ adjusted for low stimulus uptake was $800 \mathrm{~ms}$, it approximately reflects the overall half-life due to deactivation of the active pheromone bound to PBP, the species FA, FB, FAR, FAR' and FBN (Fig. 6a, b). Finally, the average halflife of the chemically intact but deactivated pheromone bound to the scavenger PBP is about $5 \mathrm{~min}$.

Further work

The modelling demonstrates the gaps of our knowledge and may help to find strategies for further work. Certainly it would be most desirable to have a complete set of biochemical, electrophysiological and fine-structural data for one animal species. Quantitative data on the interaction of binding protein, SNMP, receptor molecule and ion channel are needed. The process of pheromone deactivation is an essential postulate that needs to be experimentally verified; the proposed mechanism needs to be tested. An alternative model without pheromone deactivation has not been published. How PBP and bovine serum albumin protect the pheromone from enzymatic degradation seems an interesting question of molecular biophysics.

Acknowledgments The computer program was supplied by John Thorson (described in Kaissling 2001) who passed away in June 2008. I have much to thank him not only for his cooperation over the years and his painstaking, uncompromising criticism but also for his generous and humorous discussion. Much gratitude for the help for clarity and linguistic improvement goes to Ann Biederman-Thorson, also for checking an earlier version of this manuscript. Thanks for discussion and help to many colleagues, among them Walter S. Leal, Jean-Pierre Rospars, John G. Hildebrand, one unknown referee, and last but not least Friedrich Barth for invaluable advice to improve the structure of the paper.

Open Access This article is distributed under the terms of the Creative Commons Attribution Noncommercial License which permits any noncommercial use, distribution, and reproduction in any medium, provided the original author(s) and source are credited.

\section{Appendix A: Calculation of model parameters}

Determination of special physiological quantities

A few physiological quantities- $Q_{1}, Q_{3}, k_{\text {fall }}, U_{\text {sat }}$-will be described in the following, that allow several model parameters to be calculated, e.g. the in vivo concentration of the PBP $\left(A_{\mathrm{tot}}\right)$, parameters of the deactivation process and the fictive concentrations of the receptor molecules. 
$Q_{1}$, the fraction of pheromone adsorbed protected from degradation

In vivo the pheromone degradation clearly proceeds at two very different velocities as measured in living antennae of $B$. mori and A. polyphemus by Kasang and co-workers (1971-1989). The re-evaluated curves of pheromone degradation in both species show an initial, very fast decay by about $17 \%$ of the adsorbed pheromone and a subsequent slow decay of the remaining $83 \%\left(=Q_{1}\right)$ of the pheromone with a half-life of $4.5 \mathrm{~min}$ (Fig. 15). In the chemical model, the high velocity reflects the degradation due to the direct encounter of the incoming free pheromone with the degrading enzyme (E) (see “Modelling of Kasang's curves" in Fig. 15, inset). The change to the slower velocity occurs if $83 \%$ of the pheromone is bound to the PBP and thereby largely protected from the enzyme.

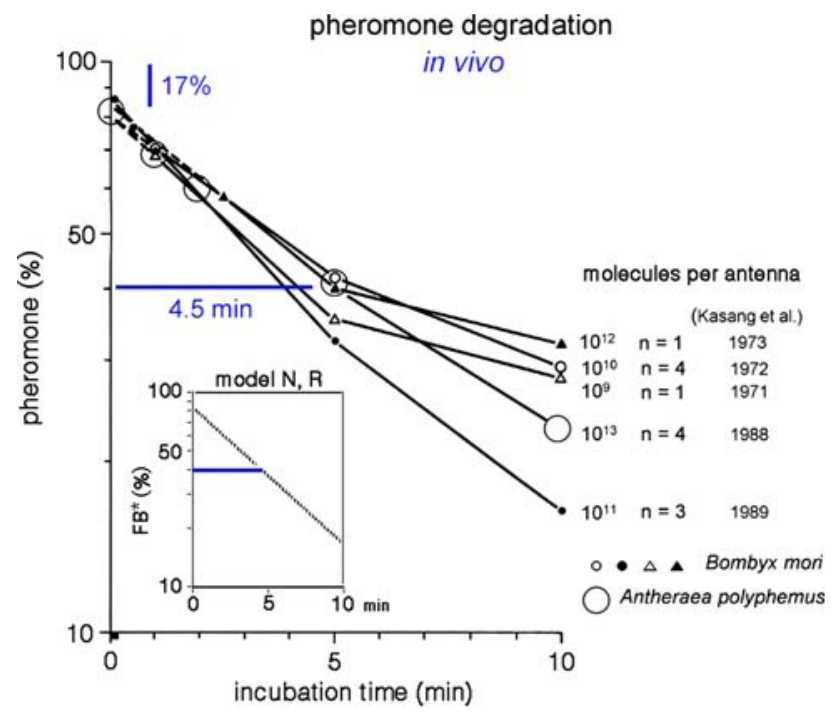

Fig. 15 Biphasic enzymatic pheromone degradation in vivo. Groups of freshly excised antennae of Bombyx mori and Antheraea polyphemus were exposed for $10 \mathrm{~s}$ to airborne stimuli with ${ }^{3} \mathrm{H}$-labeled pheromone, at uptakes eliciting half-maximal to maximal responses. The largest load of $10^{12}$ stimulus molecules per antenna of Bombyx mori and $10^{13}$ in A. polyphemus was obtained at an uptake of about $100 \mu \mathrm{M} / \mathrm{s}$. After incubation for $1 \mathrm{~s}$ and $10 \mathrm{~min}$ the antennae were dropped into organic solvent. The eluted radioactive material was analysed by thin-layer chromatography. Ordinate: percentage eluted radioactivity with intact pheromone. Each data point was obtained with $n=1$ to $n=4$ groups of 10-100 antennae per group. Data from Kasang (1971, 1973), Kasang and Kaissling (1972), and Kasang et al. (1988, 1989b). Inset Plotted is the model time-course of $F B^{*}$ (pheromone bound to $B^{*}$ ) as percentage of total pheromone adsorbed at an uptake of $1 \mu \mathrm{M} / \mathrm{s}$ for $10 \mathrm{~s}$. After adjusting $k_{11}=k_{9} / 20,000$ the time course of $F B^{*}$ reflects the biphasic decrease of intact pheromone on living antennae measured experimentally
$Q_{3}$, the fraction of pheromone molecules adsorbed eliciting receptor-neuron responses

$Q_{3}=0.25$ represents the fraction of pheromone molecules adsorbed on the hair sensilla that produce cell excitations. This fraction was determined for the silkmoth $B$. mori by counting nerve impulses at low stimulus intensities, eliciting one or fewer nerve impulses per second and per receptor-neuron. The release of stimulus molecules from the odour source and their adsorption on the antennae was measured using ${ }^{3} \mathrm{H}$-labelled pheromone (Kaissling and Priesner 1970; Kaissling 1971, 1987). Because not every activation event might elicit a nerve impulse, $Q_{3}$ serves as a minimum value.

\section{$k_{\text {fall, }}$ the apparent rate constant of the fall of FAR'}

The fall of $F A R^{\prime}$ is caused by the stimulus deactivation. Its apparent rate constant $k_{\text {fall }}$ may be obtained from the apparent half-life of the activated pheromone-receptor complex $\left(t_{1 / 2 F A R^{\prime} \text { fall }}\right)$,

$k_{\text {fall }}=-\mathrm{d} F A R^{\prime} /\left(\mathrm{d} t \cdot F A R^{\prime}\right)=\ln 2 / t_{1 / 2 F A R^{\prime} \text { fall }}$

$t_{1 / 2 F A R^{\prime} \text { fall }}$ may be determined from the decline of the receptor-potential after stimulus offset. From the measured steady dose-response curve, we find the receptor-potential amplitude for half of the stimulus uptake (Fig. 16). Assuming rapid intracellular signalling this amplitude is reached at $t_{1 / 2 F A R^{\prime} \text { fall }}$ after stimulus offset.

This half-life was determined for the pheromone component $(Z, E)-6,11$-hexadecadienyl actetate of $A$. polyphemus. With stimulus uptakes from $U=10^{-4} \mu \mathrm{M} / \mathrm{s}$ up to $U_{\text {sat }}=30 \mu \mathrm{M} / \mathrm{s}$ the values of $t_{1 / 2 F A R^{\prime} \text { fall }}$ increased from 0.5 up to $2 \mathrm{~s}$ (Fig. 4d in Kaissling 1998b). For the chemical model we use an adjusted half-time of $t_{1 / 2 F A R^{\prime} \text { fall }}=0.8 \mathrm{~s}$ (i.e. $\left.k_{\text {fall }}=0.87 / \mathrm{s}\right)$ found at a medium uptake $(0.01 \mu \mathrm{M} / \mathrm{s})$, the "adjustment uptake" (Fig. 1a).

In the following, we derive the relationships of $k_{\text {fall }}$ and the parameters of the deactivation process. Modelling shows (for $U<<U_{\text {sat }}$ ) that the half-lives of $F A R, F A, F B$ and also of $F B N$ are similar to that of $F A R^{\prime}$ (Fig. 6a, b). Therefore, $k_{\text {fall }}$ is the approximate velocity of deactivation $-\mathrm{d}(F A+F B) / \mathrm{d} t \approx \mathrm{d} F B^{*} / \mathrm{d} t$ related to the sum $F B+F A$. This sum comprises most of the pheromone on the antenna that is not yet deactivated ( $>94 \%$ for model $\mathrm{N}$, and $>97 \%$ for model $\mathrm{R}$, from Table 1)

$k_{\mathrm{fall}} \approx \mathrm{d} F B^{*} /(\mathrm{d} t(F B+F A))$.

For model $\mathrm{N}$ the velocity of deactivation is $\mathrm{d} F B^{*} / \mathrm{d} t=k_{8 N} F B N$. 
half-life of active pheromone

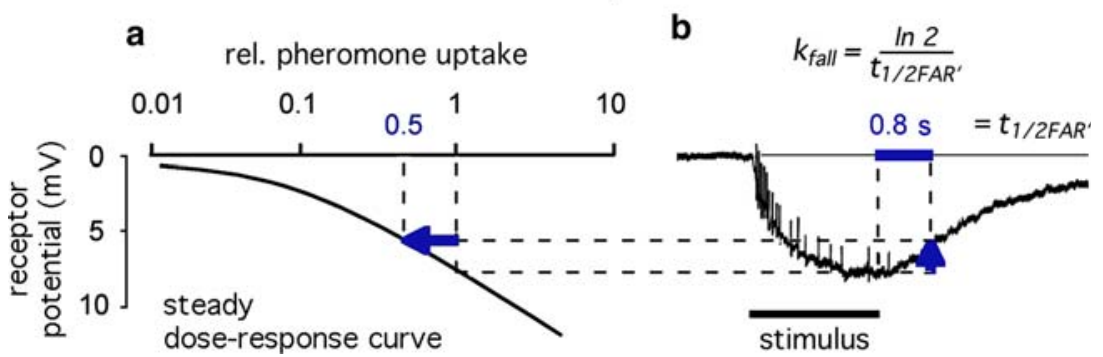

Fig. 16 The half-life of the activated pheromone-PBP-receptor complex $\left(t_{1 / 2 F A R^{\prime}}\right)$ may be determined from the steady dose-response curve (a) and from the fall of the receptor-potential after stimulus offset (b). We assume that the relationship between the amplitude of the potential and the concentration $F A R^{\prime}$ is the same during transients as in the steady state (see text). Thus, from the steady dose-response curve we may find the $\mathrm{mV}$-amplitude at which the concentration of $F A R^{\prime}$ falls to half of its "steady" value. This amplitude is reached at $t_{1 / 2 F A R^{\prime}}$ after stimulus offset
From Eqs. 13, 29, and 30 we find

$k_{\text {fall }} \approx k_{8 N} F B \cdot N /\left(K_{\mathrm{m} 7,8}(F B+F A)\right)$.

For small $F B N / N$ (or $U<<U_{\text {sat }}$ ) we set approximately $N \approx N_{\text {tot }}$, and with Eqs. 6 and 7 we arrive at

$k_{\text {fall }} \approx k_{8 N} N_{\text {tot }}\left(1-Q_{6}\right) / K_{\mathrm{m} 7,8}$.

For model R, with the receptor molecule as enzyme the velocity of deactivation is

$\mathrm{d} F B^{*} / \mathrm{d} t=k_{8 R} F A R$.

With Eqs. 17, 29, and 33 we get

$k_{\text {fall }} \approx k_{8 R} F A \cdot R /\left(K_{\mathrm{m} 5,8}(F B+F A)\right)$,

For small $F A R / R$, when $R$ is about equal to $R_{\text {tot }}$, and with Eq. 7 we arrive at approximately

$k_{\text {fall }} \approx k_{8 R} R_{\mathrm{tot} R} Q_{6} / K_{\mathrm{m} 5,8}$.

$U_{\text {sat }}$, stimulus uptake producing saturation of pheromone deactivation

Olfactory "flux detectors" with enzymatic stimulus deactivation (see "Description of the models") show a maximum occupation of the deactivating enzyme at the "saturating stimulus uptake" $U_{\text {sat }}$. Either catalyst, i.e. N and $\mathrm{R}$ in the respective models, reaches its maximum catalytic velocity

$V_{\text {max }}=k_{8 N} N_{\text {tot }} \quad($ for model $\mathrm{N})$,

$V_{\max }=k_{8 R} F A R_{\max } \quad($ for model $\mathrm{R})$.

Because only the fraction $Q_{1}$ of pheromone undergoes the deactivation, we find

$V_{\text {max }}=Q_{1} U_{\text {sat }}$.

As $U_{\text {sat }}$ we chose an uptake close to the saturation of the dose-response curve of the receptor-potential of $A$. polyphemus, i.e. $U_{\text {sat }}=30 \mu \mathrm{M} / \mathrm{s}$ (as in Kaissling 2001).
This value may be considered as a minimum because the receptor-potential amplitude theoretically saturates at uptakes lower than needed for the maximal receptormolecule occupation (Kaissling 1977).

Calculated model parameters

Several model parameters may be calculated from the above special physiological quantities together with directly determined parameters. Since a complete set of appropriate data of a single species does not exist, the data are taken from the two species of moths. Therefore, the resulting parameters must be considered as preliminary figures.

$A_{\text {tot }}$, the in vivo PBP concentration

Kasang's in vivo results together with Vogt's in vitro data on pheromone degradation and Leal's pheromone-PBP binding rate constants allow the in vivo PBP concentration $A_{\text {tot }}$ to be estimated. We assume that the incoming pheromone molecules undergo one of two reactions only; they are either enzymatically degraded or bound to PBP. The velocities of the two processes are expressed by the following equations. At low-stimulus intensities we set $E=E_{\text {tot }}$ and obtain the degradation velocity (production of metabolite $\mathrm{M}$ )

$\mathrm{d} M / \mathrm{d} t=k_{10} F \cdot E_{\mathrm{tot}} / K_{\mathrm{m} 9,10}=\left(1-Q_{1}\right) U$.

The velocity of pheromone-PBP association is

$(\mathrm{d} F B+\mathrm{d} F A) / \mathrm{d} t=\left(k_{2}+k_{3} / C\right) F \cdot A_{\text {tot }}=Q_{1} U$.

From Eqs. 39 and 40 we obtain an equation with which $A_{\text {tot }}$ can be calculated:

$A_{\mathrm{tot}}=\frac{k_{10} E_{\mathrm{tot}} Q_{1}}{\left(k_{2}+\frac{k_{3}}{C}\right) K_{\mathrm{m} 9,10}\left(1-Q_{1}\right)}$ 
With the model parameters $k_{10}=127 / \mathrm{s}, E_{\mathrm{tot}}=0.5 \mu \mathrm{M}$, $K_{\mathrm{m} 9,10}=1.2 \mu \mathrm{M}, \quad C=10 \quad$ (from A. polyphemus), $k_{2}=0.068 /(\mathrm{s} \mu \mathrm{M}), k_{3}=0.0066 /(\mathrm{s} \mu \mathrm{M}$ ) (from B. mori), and $Q_{1}=0.83$ (from both species) we find $A_{\text {tot }}=3.8 \mathrm{mM}$. With $k_{10}=98 / \mathrm{s}, \quad E_{\text {tot }}=1 \mu \mathrm{M}, \quad K_{\mathrm{m} 9,10}=2.2 \mu \mathrm{M}$ from Vogt et al. (1985) we find $\mathrm{A}_{\mathrm{tot}}=3.2 \mathrm{mM}$.

$N_{t o t}, k_{7}, k_{-7}$, and $k_{8 N}$, the parameters of the deactivation process of model $N$

Two of the parameters are free; we chose $N_{\text {tot }}=0.5 \mu \mathrm{M}$ and $k_{-7}=300 / \mathrm{s}$. As tested by the computer program, the output of the model is negligibly affected by choosing the free parameters (not shown). From Eqs. 36 and 38 we find the catalytic rate constant

$k_{8 N}=U_{\text {sat }} Q_{1} / N_{\text {tot }}=49.8 / \mathrm{s}$

We find from Eqs. 32 and 42 the Michaelis constant of the hypothetical enzyme $\mathrm{N}$

$K_{m 7,8}=U_{\text {sat }}\left(1-Q_{6}\right) Q_{1} / k_{\text {fall }}=21.87 \mu \mathrm{M}$

Using Eq. 13 we find $k_{7}=15.99 /(\mathrm{s} \mu \mathrm{M})$.

$k_{8 R}$, the catalytic rate constant of pheromone deactivation for model $R$

$k_{8 R}$ may be calculated by combining Eqs. 17, 36 and 54 . We obtain

$Q_{7}\left(k_{-5}+k_{8 R}\right) / k_{8 R}=Q_{3} / Q_{1}$.

and from this equation, we derive

$k_{8 R}=\frac{G}{2}+\sqrt{\frac{G^{2}}{4}+H}=\frac{41.6}{\mathrm{~s}}$

with $G=k_{6}\left(Q_{1} / Q_{3}-1\right)-k_{-5}$ and $H=k_{6} k_{-5} Q_{1} / Q_{3}$, with data from $B$. mori.

By combining Eqs. 10, 35, 37 and 38 we find the Michaelis constant of deactivation for model $\mathrm{R}$

$K_{\mathrm{m} 5,8}=\frac{U_{\text {sat }} Q_{1} Q_{6}}{k_{\text {fall }} Q_{4}}=7.91 \mu \mathrm{M}$

$k_{5}$, the association rate constant of the complex $F A$ and the receptor molecule $R$

The association rate constant $k_{5 N}$ for model $\mathrm{N}$ may be calculated with the assumption of a linear dependence of $F A R^{\prime}$ on $U$ (assumption $\mathrm{F}$ in Kaissling 2001), i.e. assuming $Q_{8}=1$ (Eq. 71). With values of $Q_{8}<1$ the activated receptor molecules $\mathrm{FAR}^{\prime}$ would approach saturation too early, i.e. at uptakes below $U_{\text {sat }}$ (Kaissling 1998a). For $Q_{8}=1$, we obtain from Eqs. 8, 43, and 71

$k_{5 N}=\frac{k_{-5} Q_{4} k_{\text {fall }}}{U_{\text {sat }} Q_{1} Q_{6}}=\frac{0.974}{\mathrm{~s} \mu \mathrm{M}}$
The respective rate constant $k_{5 R}$ for model $\mathrm{R}$ results from Eqs. 17 and 46

$k_{5 R}=\frac{\left(k_{-5}+k_{8 R}\right) Q_{4} k_{\mathrm{fall}}}{U_{\mathrm{sat}} Q_{1} Q_{6}}=\frac{6.23}{\mathrm{~s} \mu \mathrm{M}}$

$R_{\text {tot }}$, the fictive concentration of receptor molecules

Estimating the fictive concentration of receptor molecules (in $2.6 \mathrm{pl}$ ) can be done using the rate of pheromone deactivation $\mathrm{d} F B^{*} / \mathrm{d} t$ and the rate of receptor molecule activation $\mathrm{d} F A R^{\prime} / \mathrm{d} t$. Because practically all of the active pheromone on the antenna is bound to the two PBP forms (A and B), the rate of pheromone deactivation (during the steady state) is approximately $\mathrm{d} F B^{*} / \mathrm{d} t=k_{\text {fall }}(F B+F A) \approx Q_{1} U$

We find for model $\mathrm{N}$ the rate of receptor molecule activation at low stimulus uptake, where $R \approx R_{\mathrm{tot}}$, and for $k_{\text {fall }}=0.87 / \mathrm{s}$

$\mathrm{d} F A R^{\prime} / \mathrm{d} t \approx k_{5 N} F A \cdot R_{\mathrm{tot} N} Q_{5}=Q_{3} U$

From Eqs. 20 and 55 we obtain

$\frac{k_{5 N} F A \cdot R_{\mathrm{tot} N} Q_{5}}{k_{\mathrm{fall}}(F B+F A)}=\frac{Q_{3} U}{Q_{1} U}$

This reveals with Eqs. 7 and 47

$R_{\text {tot } N}=\frac{U_{\text {sat }} Q_{3}}{k_{-5} Q_{4} Q_{5}}=1.66 \mu \mathrm{M}$

For the model $\mathrm{R}$ the rate of receptor molecule activation $\mathrm{d} F A R^{\prime} / \mathrm{d} t$ at low-stimulus uptake is

$\mathrm{d} F A R^{\prime} / \mathrm{d} t \approx k_{5 R} F A \cdot R_{\mathrm{tot} R} Q_{7}=Q_{3} U$

Using Eqs. 7, 48, 49 and 53 we arrive at

$R_{\mathrm{tot} R}=\frac{\mathrm{U}_{\mathrm{sat}} Q_{3}}{\left(k_{-5}+k_{8 R}\right) Q_{4} Q_{7}}=0.70 \mu \mathrm{M}$

\section{Appendix B: Model S, with deactivation as a spontaneous process}

Pheromone deactivation

In model $\mathrm{S}$ the enzyme $\mathrm{N}$ and reactions 7 are absent. Deactivation of the complex FB occurs by a first-order reaction $\mathrm{FB} \Rightarrow \mathrm{FB}^{*}$, with the rate constant $k_{8 s}$. The velocity of deactivation during steady state is

$\mathrm{d} F B^{*} / \mathrm{d} t=k_{8 S} F B \approx Q_{1} U$

From Eqs. 29 and 55 we find

$k_{\mathrm{fall}}=k_{8 S} F B /(F B+F A)$

Using Eqs. 6 and 7 we obtain

$k_{8 S}=k_{\text {fall }} /\left(1-Q_{6}\right)=1.14 / \mathrm{s}$ 
$k_{5 S}$, the association rate constant of FA and R

For model $\mathrm{S}$ we chose $U_{1 / 2 \max }=30 \mu \mathrm{M} / \mathrm{s}$. Using Eqs. 7, 57, 62 and the dissociation constant

$K_{\mathrm{d} 5 S}=k_{-5} / k_{5 S}$

we may calculate the association rate constant $k_{5 \mathrm{~S}}$ of FA and $\mathrm{R}$

$k_{5 S}=\frac{k_{-5} Q_{4} k_{\text {fall }}}{U_{1 / 2 \max } Q_{1} Q_{6}}=\frac{0.974}{\mathrm{~s} \mu \mathrm{M}}$

Numerically, $k_{5 S}$ is identical with $k_{5 N}$, (Eq. 47). Consequently, $K_{\mathrm{d} 5 S}=K_{\mathrm{d} 5 N}=7.91 \mu \mathrm{M}$.

$R_{\mathrm{tot} S}$, the fictive concentration of receptor molecules

$R_{\mathrm{tot} S}$ may be obtained in the same way as $\mathrm{R}_{\mathrm{tot} N}$ (cf. Appendix A), from Eqs. 7, 50 and 53, but with Eq. 59 instead of Eq. 47. We arrive at a value numerically equal to $R_{\text {tot } N}$ (cf. Eq. 52)

$R_{\mathrm{tot} S}=\frac{U_{1 / 2 \mathrm{max}} Q_{3}}{k_{-5} Q_{4} Q_{5}}$

The steady dose-response relation

The relation of $F A R^{\prime} / F A R^{\prime}{ }_{\text {max }}$ and $U$ may be obtained from Eq. 55 and an equivalent of Eq. 66

$\frac{F A R^{\prime}}{F A R_{\max }^{\prime}}=\frac{1}{\frac{K_{\mathrm{d} 5 S} Q_{4} K_{4} C k_{8 S}}{U Q_{1}}+1}$

In contrast to the models $\mathrm{N}$ and $\mathrm{R}$, this relation is a hyperbolic (logistic) function that may be characterizied by the uptake $U_{1 / 2 \max }$ for half maximum $F A R^{\prime} / F A R_{\text {max }}^{\prime}$. From Eq. 61 we obtain for

$U=U_{1 / 2 \max }=\frac{K_{\mathrm{d} 5 S} Q_{4} K_{4} C k_{8 S}}{Q_{1}}$

The linear slope of the steady dose-response relation at $U<<U_{1 / 2 \max }$ is (from Eqs. 61, 62 and an equiv. of Eq. 73)

$\frac{F A R^{\prime}}{U}=\frac{F A R_{\max }^{\prime}}{U_{1 / 2 \max }}=\frac{R_{\mathrm{tot} S}\left(1-Q_{4}\right)}{U_{1 / 2 \max }}$

which is numerically the same as for model $\mathrm{N}$ (see Eq. 74).

\section{Appendix C: The "steady" dose-response relationship}

\section{Model N}

The steady dose-response relation of $F A R^{\prime} / F A R_{\text {max }}^{\prime}$ and $U$ was first derived for a simplified reaction scheme (Eq. 13 in Kaissling 1998a). The dependence of $F A R^{\prime} / F A R_{\text {max }}^{\prime}$ on $U$ can be derived for model $\mathrm{N}$ as follows. With Eqs. 9 and 10 we find

$\frac{F A R^{\prime}}{F A R_{\max }^{\prime}}=\frac{F A R}{R_{\mathrm{tot}} Q_{4}}$

and with Eq. 12

$\frac{F A R^{\prime}}{F A R_{\max }^{\prime}}=\frac{1}{\frac{R Q_{4}}{F A R}+1}$

With Eqs. 6 and 8 we find

$\frac{F A R^{\prime}}{F A R_{\max }^{\prime}}=\frac{1}{\frac{K_{\mathrm{d} 5 N} Q_{4} K_{4} C}{F B}+1}$

With Eq. 13 and

$N_{\text {tot }}=N+F B N$

we find

$\frac{F A R^{\prime}}{F A R_{\max }^{\prime}}=\frac{1}{\frac{K_{\mathrm{d} 5 N} Q_{4} K_{4} C}{K_{\mathrm{m} 7,8}}\left(\frac{N_{\mathrm{tot}}}{F B N}-1\right)+1}$

A steady amplitude of $F A R^{\prime} / F A R_{\text {max }}^{\prime}$ is expected if the rates of deactivation and uptake are about equal for the condition $U Q_{1}<k_{8 N} N_{\text {tot }}$

$\mathrm{d} F B^{*} / \mathrm{d} t=k_{8 N} F B N \approx U Q_{1}$

From Eqs. 68 and 69, and with Eqs. 36 and 38 we find

$\frac{F A R^{\prime}}{F A R_{\max }^{\prime}}=\frac{1}{\frac{K_{\mathrm{d} 5} Q_{4} K_{4} C}{K_{\mathrm{m} 7,8}}\left(\frac{U_{\mathrm{sat}}}{U}-1\right)+1}$

(cf. Eqs. 4, 6 in Kaissling 2001).

The shape of the dependence of $F A R^{\prime}$ on $U$ varies with the ratio

$\frac{K_{\mathrm{d} 5} Q_{4} K_{4} C}{K_{\mathrm{m} 7,8}}=Q_{8}$

With $Q_{8}<1$ the function $F A R^{\prime} / U$ saturates similar to a hyperbolic (or "logistic") function. The function rises linearly up to saturation with $Q_{8}=1$, and it rises steeper than linear with $Q_{8}>1$ (Kaissling 1998a). In all cases, a maximum value of activated receptor molecules $F A R_{\text {max }}^{\prime}$ is reached with long-time stimulation at the "saturating stimulus uptake" $U_{\text {sat }}$ at which the enzyme $\mathrm{N}$ is saturated. At low uptake the curve always rises linearly. For small $U / U_{\text {sat }}$ we find from Eq. 71

$F A R^{\prime}=\frac{F A R_{\text {max }}^{\prime}}{Q_{8} U_{\text {sat }}} U$

(see Eq. 19, Kaissling 1998a, or Eq. 10, Kaissling 2001). With Eqs. 9 and 10 we find

$F A R_{\max }^{\prime}=R_{\text {tot } N}\left(1-Q_{4}\right)$. 
The linear part of the function $F A R^{\prime} / U$, when $U<<U_{\text {sat }}$, has the slope

$\frac{F A R^{\prime}}{U}=\frac{R_{\text {tot } N}\left(1-Q_{4}\right)}{Q_{8} U_{\text {sat }}}=0.00808 \mathrm{~s}$

For model $\mathrm{N}$ we assume $Q_{8}=1$, i.e. a linear slope of the function $F A R^{\prime} / U$.

\section{Model R}

The steady relation of $F A R^{\prime} / F A R^{\prime}$ max and $U$ can be derived for model $\mathrm{R}$ as follows. A steady amplitude of $\mathrm{FAR}^{\prime} /$ $\mathrm{FAR}_{\text {max }}^{\prime}$ is expected for the condition $U Q_{1}<k_{8 R} F A R_{\max }$ $\mathrm{d} F B^{*} / \mathrm{d} t=k_{8 R} F A R \approx U Q_{1}$

With Eqs. 75 and 64 we obtain the (linear) function

$$
\frac{F A R^{\prime}}{F A R_{\max }^{\prime}}=\frac{U Q_{1}}{k_{8 R} R_{\mathrm{tot} R} Q_{4}}
$$

With Eqs. 9, 33 and 34 we arrive at

$$
\frac{F A R^{\prime}}{F A R_{\text {max }}^{\prime}}=\frac{U}{U_{\text {sat }}}
$$

With Eqs. 76, 9 and 10 the slope of $F A R^{\prime}$ versus $U$ is

$$
\frac{F A R^{\prime}}{U}=\frac{Q_{1}}{k_{8 R} K_{6}}=0.00342 \mathrm{~s}
$$

\section{References}

Benton R, Vannice KS, Vosshall L (2007) An essential role for a CD36-related receptor in pheromone detection in Drosophila. Nature 450:203-289

Campanacci V, Longhi S, Nagnan-Le Meillour P, Cambillau C, Tegoni M (1999) Recombinant pheromone binding protein 1 from Mamestra brassicae (MbraPBP1). Functional and structural characterization. Eur J Biochem 264:707-716

Damberger FF, Ishida Y, Leal WS, Wüthrich K (2007) Structural basis of ligand binding and release in insect pheromone-binding proteins: NMR structure of Antheraea polyphemus $\mathrm{PBP} 1$ at $\mathrm{pH}$ 4.5. J Mol Biol 373:811-819

De Kramer JJ, Hemberger J (1987) The neurobiology of pheromone reception. In: Prestwich GD, Blomquist GJ (eds) Pheromone biochemistry. Academic Press, New York, pp 433-472

Dobritsa AA, Van der Goes van Naters W, Warr CG, Steinbrecht RA, Carlson JR (2003) Integrating the molecular and cellular basis of odor coding in the Drosophila antenna. Neuron 37:827-841

Dratz EA, Hargrave PA (1983) The structure of rhodopsin and the rod outer segment disk membrane. Trends Biochem Sci 8:128

Du GH, Prestwich GD (1995) Protein structure encodes the ligand binding specificity in pheromone binding proteins. Biochemistry 34:8726-8732

Eschrich R, Kumar GL, Keil TA, Guckenberger R (1998) Atomic force microscopy on the olfactory dendrites of the silkmoths Antheraea polyphemus and A. pernyi. Cell Tiss Res 294:179-185

Forstner M, Gohl T, Breer H, Krieger J (2006) Candidate pheromone binding proteins of the silkmoth Bombyx mori. Invert Neurosci 6:177-187
Graeter F, Xu W, Leal W, Grubmueller H (2006) Pheromone discrimination by the pheromone-binding protein of Bombyx mori. Structure 14:1577-1586

Grosse-Wilde E, Svatos A, Krieger J (2006) A pheromone-binding protein mediates the bombykol-induced activation of a pheromone receptor in vitro. Chem Senses 31:547-555

Gu Y, Lucas P, Rospars J-P (2009) Computational model of the insect pheromone transduction cascade. Plos Comput Biol 5(3): e1000321 (Epub 20 March 2009)

Hallem EA, Ho MG, Carlson JR (2004) The molecular basis of odor coding in the Drosophila antenna. Cell 117:965-979

Hansen K (1984) Discrimination and production of disparlure enantiomers by the gypsy moth and the nun moth. Physiological Entomol 9:9-18

Horst R, Damberger F, Luginbühl P, Güntert P, Peng G, Nikonova L, Leal W, Wüthrich K (2001a) NMR structure reveals intramolecular regulation mechanism for pheromone binding and release. Proc Natl Acad Sci USA 98:14374-14379

Horst R, Damberger F, Peng G, Nikonova L, Leal WS, Wüthrich K (2001b) NMR assignment of the A form of the pheromonebinding protein of Bombyx mori. J Biomol NMR 19:79-80

Ishida Y, Leal WS (2005) Rapid inactivation of a moth pheromone. Proc Natl Acad Sci USA 102:14075-14079

Jin X, Ha TS, Smith DP (2008) SNMP is a signalling component required for pheromone sensitivity in Drosophila. PNAS 105:10995-11000

Kaissling KE (1971) Insect olfaction. In: Beidler LM (ed) Handbook of sensory physiology IV. Springer Verlag, Heidelberg, pp 351431

Kaissling KE (1972) Kinetic studies of transduction in olfactory receptors of Bombyx mori. In: Schneider D (ed) Olfaction and Taste IV. Wissenschaftl Verlagsges, Stuttgart, pp 207-213

Kaissling KE (1974) Sensory transduction in insect olfactory receptors. In: Jaenicke L (ed) 25. Mosbacher Coll Ges Biolog Chemie, biochemistry of sensory functions. Springer, Berlin, pp 243-273

Kaissling KE (1977) Structures of odour molecules and multiple activities of receptor cells. In: Le Magnen J, MacLeod P (eds) Olfaction and taste VI. Inf. Retrieval, London, pp 9-16

Kaissling KE (1987) RH Wright lectures on insect olfaction. Colbow K (ed) Simon Fraser University, Burnaby, pp 1-190

Kaissling KE (1995) Single unit and electroantennogram recordings in insect olfactory organs. In: Spielman AI, Brand JG (eds) Experimental cell biology of taste and olfaction: Current techniques and protocols. CRC Press, Boca Raton, pp 361-386

Kaissling KE (1997) Pheromone-controlled anemotaxis in moths. In: Lehrer M (ed) Orientation and communication in arthropods. Birkhaeuser Verlag, Basel, pp 343-374

Kaissling KE (1998a) Flux detectors versus concentration detectors: two types of chemoreceptors. Chem Senses 23:99-111

Kaissling KE (1998b) Pheromone deactivation catalyzed by receptor molecules: a quantitative kinetic model. Chem Senses 23:385395

Kaissling KE (2001) Olfactory perireceptor and receptor events in moths: a kinetic model. Chem Senses 26:125-150

Kaissling KE (2004) Physiology of pheromone reception in insects (an example of moths). Anir 6:73-91

Kaissling KE (2009) The sensitivity of the insect nose: The example of Bombyx mori. In: Marco S, Gutierrez-Galvez A (eds) Biologically inspired signal processing for chemical sensing, SCI 188. Springer, Heidelberg, pp 45-52

Kaissling KE, Kumar GL (1997) Densities of putative receptor molecules and ion channels in dendritic membranes of pheromone receptor cells of moths. In: Elsner $\mathrm{N}$ and Wässle $\mathrm{H}$ (eds) Proc 25th Göttingen Neurobiol Conf, Thieme, Stuttgart, vol II, p 429 
Kaissling KE, Leal WS (2004) Biologische Nanokapseln für Duftstoffe. Naturwiss Rundschau 57:66-71

Kaissling KE, Priesner E (1970) Die Riechschwelle des Seidenspinners. Naturwissenschaften 57:23-28

Kaissling KE, Thorson J (1980) Insect olfactory sensilla: Structural, chemical and electrical aspects of the functional organisation. In: Sattelle DB, Hall LM, Hildebrand JG (eds) Receptors for neurotransmitters, hormones and pheromones in Insects. Elsevier/North-Holland Biomedical Press, Amsterdam, pp 261-282

Kaissling KE, Kasang G, Bestmann HJ, Stransky W, Vostrowsky O (1978) A New Pheromone of the Silkworm Moth Bombyx mori. Sensory pathway and behavioral effect. Naturwissenschaften 65:382-384

Kaissling KE, Klein U, de Kramer JJ, Keil TA, Kanaujia S, Hemberger J (1985) Insect olfactory cells: electrophysiological and biochemical studies. In: Changeux JP, Hucho F (eds) Molecular basis of nerve activity. Proc of the Internat Symp in Memory of D. Nachmansohn. Walter de Gruyter, Berlin, pp $173-183$

Kaissling KE, Meng LZ, Bestmann HJ (1989) Responses of bombykol receptor cells to $(Z, E)-4,6$-hexadecadiene and linalool. J Comp Physiol A 165:147-154

Kanaujia S, Kaissling KE (1985) Interactions of pheromone with moth antennae: adsorption, desorption and transport. J Insect Physiol 31:71-81

Kasang G (1971) Bombykol reception and metabolism on the antennae of the silkmoth Bombyx mori. In: Ohloff G, Thomas AF (eds) Gustation and olfaction. Academic Press, London, pp 245-250

Kasang G (1973) Physikochemische Vorgänge beim Riechen des Seidenspinners. Naturwissenschaften 60:95-101

Kasang G, Kaissling KE (1972) Specificity of primary and secondary olfactory processes in Bombyx antennae. In: Schneider D (ed) Intern Symp Olfaction and Taste IV. Wissensch Verlagsgesellsch Stuttgart. pp 200-206

Kasang G, von Proff L, Nicholls M (1988) Enzymatic conversion and degradation of sex pheromones in antennae of the male silkworm moth Antheraea polyphemus. Z Naturforsch 43c:275-284

Kasang G, Nicholls M, Keil TA, Kanaujia S (1989a) Enzymatic conversion of sex pheromones in olfactory hairs of the male silkworm moth Antheraea polyphemus. Z Naturforsch 44c:920 926

Kasang G, Nicholls M, von Proff L (1989b) Sex pheromone conversion and degradation in antennae of the male silkworm moth Bombyx mori L. Experientia 45:81-87

Keil TA (1984a) Surface coats of pore tubules and olfactory sensory dendrites of a silkmoth revealed by cationic markers. Tissue Cell 16:705-717

Keil TA (1984b) Reconstruction and morphometry of silkmoth olfactory hairs: a comparative study of sensilla trichodea on the antennae of male Antheraea polyphemus and Antheraea pernyi (Insecta, Lepidoptera). Zoomorphology 104:147-156

Klein U (1987) Sensillum-lymph proteins from antennal olfactory hairs of the moth Antheraea polyphemus (Saturniidae). J Insect Biochem 17:1193-1204

Klusák V, Havlas Z, Rulísek L, Vondrásek J, Svatos A (2003) Sexual attraction in the silkworm moth: nature of binding of bombykol in pheromone binding protein - an ab initio study. Chem Biol $10: 331-340$

Kowcun A, Honson N, Plettner E (2001) Olfaction in the gypsy moth, Lymantria dispar: effect of $\mathrm{pH}$, ionic strength, and reductants on pheromone transport by pheromone-binding proteins. J Biol Chem 276:44770-44776

Laughlin JD, Ha TS, Jones DNM, Smith DP (2008) Activation of pheromone-sensitive neurons is mediated by conformational activation of pheromone-binding protein. Cell 133:1255-1265
Lautenschlager C, Leal WS, Clardy J (2005) Coil-to-helix and ligand release of Bombyx mori pheromone-binding protein. Biochem Biophysic Res Commun 335:1044-1050

Leal WS (2000) Duality monomer-dimer of the pheromone-binding protein from Bombyx mori. Biochem Biophys Res Commun 268:521-529

Leal WS (2003) Proteins that make sense. In: Blomquist GJ, Vogt RG (eds) Insect pheromone biochemistry and molecular biology, the biosynthesis and detection of pheromones and plant volatiles. Elsevier Academic Press, USA, pp 447-476

Leal WS (2004) Pheromone unwrapping by pH flip-flopping. Chem Biol 11:1029-1031

Leal WS, Chen AM, Ishida Y, Chiang VP, Erickson ML, Morgan TI, Tsuruda JM (2005a) Kinetics and molecular properties of pheromone binding and release. Proc Natl Acad Sci USA 102:5386-5391

Leal WS, Chen AM, Erickson ML (2005b) Selective and $\mathrm{pH}-$ dependent binding of a moth pheromone to a pheromone-binding protein. J Chem Ecol 31:2493-2499

Maida R, Pelosi P (1989) Identification and partial purification of a pheromone-binding protein in Bombyx mori. Ital $\mathrm{J}$ Biochem $38: 211 \mathrm{~A}-213 \mathrm{~A}$

Maida R, Ziegelberger G, Steinbrecht RA, Pelosi P (1993) The pheromone-binding protein of Bombyx mori: purification, characterization, and Immunocytochemical localization. Insect Bioch Mol Biol 23:243-253

Maida R, Ziegelberger G, Kaissling KE (1995) Esterase activity in the olfactory sensilla of the silkmoth Antheraea polyphemus. Neuroreport 6:822-824

Maida R, Proebstl MT, Laue M (1997) Heterogeneity of odorantbinding proteins in the antennae of Bombyx mori. Chem Senses 22:503-515

Maida R, Ziegelberger G, Kaissling KE (2003) Ligand binding to six recombinant pheromone-binding proteins of Antheraea polyphemus and Antheraea pernyi. J Comp Physiol B 173:565-573

Maida R, Mameli M, Mueller B, Krieger J, Steinbrecht RA (2005) The expression pattern of four odorant-binding proteins in male and female silk moths, Bombyx mori. J Neurocytol 34:149-163

Meng LZ, Wu CH, Wicklein M, Kaissling KE, Bestmann HJ (1989) Number and sensitivity of three types of pheromone receptor cells in Antheraea pernyi and A. polyphemus. J Comp Physiol A 165:139-146

Minor AV, Kaissling KE (2003) Cell responses to single pheromone molecules may reflect the activation kinetics of olfactory receptor molecules. J Comp Physiol A 189:221-230

Mohl C, Breer H, Krieger J (2002) Species-specific pheromonal compounds induce distinct conformational changes of pheromone binding protein subtypes from Antheraea polyphemus. Invert Neurosci 4:165-174

Nakagawa T, Sakurai T, Nishioka T, Touhara K (2005) Insect sexpheromone signals mediated by specific combinations of olfactory receptors. Science 307:1638-1642

Oldham NJ, Krieger J, Breer H, Fischedick A, Hoskovec M, Svatos A (2000) Analysis of the silkworm moth pheromone binding protein-pheromone complex by electrospray-ionization-mass spectrometry. Angew Chemie Int Ed 39:4341-4343

Plettner E, Lazar J, Prestwich EG, Prestwich GD (2000) Discrimination of pheromone enantiomers by two pheromone binding proteins from the gypsy moth Lymantria dispar. Biochemistry 39:8953-8962

Pophof B (1998) Inhibitors of sensillar esterase reversibly block the responses of moth pheromone receptor cells. J Comp Physiol A 183:153-164

Pophof B (2002) Moth pheromone binding proteins contribute to the excitation of olfactory receptor cells. Naturwissenschaften $89: 515-518$ 
Pophof B (2004) Pheromone-binding proteins contribute to the activation of olfactory receptor neurons in the silkmoths Antheraea polyphemus and Bombyx mori. Chem Senses 29:117-126

Pophof B, Gebauer T, Ziegelberger G (2000) Decyl-thio-trifluoropropanone, a competitive inhibitor of moth pheromone receptors. J Comp Physiol A 186:315-323

Prestwich GD, Du G, LaForest S (1995) How is pheromone specificity encoded in proteins? Chem Senses 20:461-469

Rogers ME, Steinbrecht RA, Vogt RG (2001) Expression of SNMP-1 in olfactory neurons and sensilla of male and female antennae of the silkmoth Antheraea polyphemus. Cell Tissue Res 303:433-446

Sandler BH, Nikonova L, Leal WS, Clardy J (2000) Sexual attraction in the silkworm moth: structure of the pheromone-bindingprotein-bombykol complex. Chem Biol 7:143-151

Sato K, Pellegrino M, Nakagawa T, Vosshall LB, Touhara K (2008) Insect olfactory receptors are heteromeric ligand-gated ion channels. Nature 452:1002-1006

Steinbrecht RA (1970) Zur Morphometrie der Antenne des Seidenspinners. Bombyx mori L.: Zahl und Verteilung der Riechsensillen (Insecta, Lepidoptera). Z Morph Tiere 66:93-126

Steinbrecht RA (1973) Der Feinbau olfaktorischer Sensillen des Seidenspinners (Insecta, Lepidoptera). Z Zellforsch 139:533565

Steinbrecht RA (1996) Are odorant-binding proteins involved in odorant discrimination? Chemical Senses 21:719-727

Steinbrecht RA, Kasang G (1972) Capture and conveyance of odour molecules in an insect olfactory receptor. In: Schneider D (ed) Olfaction and taste IV. Wiss Verlagsges, Stuttgart, pp 193-199

Steinbrecht RA, Lee J-K, Altner H, Zimmermann B (1989) Volume and surface of receptor and auxiliary cells in hygro-/thermoreceptive sensilla of moths (Bombyx mori, Antheraea pernyi and A. polyphemus). Cell Tissue Res 255:59-67

Steinbrecht RA, Ozaki M, Ziegelberger G (1992) Immunocytochemical localization of pheromone-binding protein in moth antennae. Cell Tissue Res 270:287-302

Steinbrecht RA, Laue M, Ziegelberger G (1995) Immunolocalization of pheromone-binding protein and general odorant-binding protein in olfactory sensilla of the silkmoths Antheraea and Bombyx. Cell Tissue Res 282:203-217

Syed Z, Ishida Y, Taylor K, Kimbrell DA, Leal WS (2006) Pheromone reception in fruit flies expressing a moth's odorant receptor. PNAS 103:16538-16543
Van den Berg MJ, Ziegelberger G (1991) On the function of the pheromone binding protein in the olfactory hairs of Antheraea polyphemus. J Insect Physiol 37:79-85

Vermeulen A, Lánsky P, Tuckwell H, Rospars J-P (1997) Coding of odour intensity in a sensory neuron. BioSystems 40:203-210

Vogt RG (1987) The molecular basis of pheromone reception: its influence on behavior. In: Prestwich GD, Blomquist GJ (eds) Pheromone biochemistry. Academic Press, New York, pp 385431

Vogt RG, Riddiford LM (1981) Pheromone binding and inactivation by moth antennae. Nature (London) 293:161-163

Vogt RG, Riddiford LM (1986) Pheromone reception: a kinetic equilibrium. In: Payne TL, Birch MC, Kennedy CEJ (eds) Mechanisms in insect olfaction. Clarendon Press, Oxford, pp 201-208

Vogt RG, Riddiford LM, Prestwich GD (1985) Kinetic properties of a pheromone degrading enzyme: the sensillar esterase of Antheraea polyphemus. Proc Natl Acad Sci USA 82:8827-8831

Wicher D, Schaefer R, Bauernfeind R, Stensmyr MC, Heller R, Heinemann SH, Hansson BS (2008) Drosophila odorant receptors are both ligand-gated and cyclic-nucleotide-activated cation channels. Nature 452:1007-1011

Wojtasek H, Leal SW (1999) Conformational change in the pheromone-binding protein from Bombyx mori induced by $\mathrm{pH}$ and by interaction with membranes. J Biol Chem 274:3095030956

$\mathrm{Xu} \mathrm{W,} \mathrm{Leal} \mathrm{WS} \mathrm{(2008)} \mathrm{Molecular} \mathrm{switches} \mathrm{for} \mathrm{pheromone} \mathrm{release}$ from a moth pheromone-binding protein. Biochem Biophys Res Commun 372:559-564

Xu PX, Atkinson R, Jones DNM, Smith DP (2005) Drosophila OBP LUSH is required for activity of pheromone-sensitive neurons. Neuron 45:193-200

Zack C (1979) Sensory adaptation in the sex pheromone receptor cells of saturniid moths. Diss Fak Biol LMU München, pp 1-99

Zhou JJ, Robertson G, He X, Dufour S, Hooper AM, Pickett JA, Keep NH, Field LM (2009) Characterisation of Bombyx mori odorantbinding proteins reveals that a general odorant-binding protein discriminates between sex pheromone components. JMB 389:529-545

Ziegelberger G (1995) Redox-shift of the pheromone-binding protein in the silkmoth Antheraea polyphemus. Eur J Biochem 232:706-711 